\title{
IDENTIFICACIÓN E INVENTARIO DE POTENCIA- LES GLACIARES ROCOSOS ACTIVOS EN LOS PIRINEOS MEDIANTE FOTOINTEPRETACIÓN EN VISORES CARTOGRÁFICOS 2D Y 3D: PRIMEROS RESULTADOS
}

\author{
Josep VENTURA ROCA (jventura@telespazio.es) \\ Telespazio Ibérica (Barcelona - Madrid)
}

Recibido: 02/02/2016

Aceptado: 03/05/2016

\begin{abstract}
RESUMEN: En este artículo se inventarían un total de 69 nuevos glaciares rocosos potencialmente activos (intact rock glaciers) en los Pirineos; incluyendo a 25 de reducidas dimensiones y catalogados como lóbulos protalud y a 27 con una superficie superior a los $20.000 \mathrm{~m}^{2}$. La metodología utilizada en esta fase del estudio ha sido la fotointerpretación en visores cartográficos $2 \mathrm{D}$ y $3 \mathrm{D}$ con ortoimagenes de alta resolución. Se analizan sus principales características junto a los 18 glaciares rocosos inventariados previamente y se establecen 5 tipologías de estas geoformas; 3 de talud periglaciar y 2 de derrubios glaciogénicos. A destacar por su concentración de glaciares rocosos los nuevos macizos estudiados de Perdiguero - Gourgs Blancs y Punta Alta - Colomèrs con 10 y 8 glaciares rocosos respectivamente y la localización de diversos glaciares rocosos aislados en macizos del Pirineo Oriental (Canigó, Carlit y PuigmalCarançà).
\end{abstract}

$\boldsymbol{P A L A B R A S ~ C L A V E}$ : Fotointerpretación, intact rock glaciers, permafrost, alta montaña, Pirineos.

IDENTIFICATION AND INVENTORY OF POTENTIA ACTIVE ROCK GLACIERS IN THE PYRENEES BY PHOTO INTERPRETATION IN $2 D$ AND $3 D$ CARTOGRAPHIC VIEWERS: FIRST RESULTS

ABSTRACT: In this article a total of 69 new potentially active rock glaciers (intact rock glaciers) in the Pyrenees are inventoried; including 25 small size rock glaciers cataloged as protalus lobe and 27 with area greater than $20,000 \mathrm{~m}^{2}$. The methodology used in this phase of the study was the photo interpretation in $2 \mathrm{D}$ and $3 \mathrm{D}$ cartographic viewers using high resolution orthoimages. Its main characteristics are analyzed together with 18 rock glaciers previously inventoried and five types of these landforms are established; 3 of talus rock glaciers (periglacial origin) and 2 of debris rock glaciers (glacial origin). It is remarkable, because of their concentration of rock glaciers, the new massifs studied, Perdiguero-Gourgs Blancs and Punta AltaColomèrs, are remarkable, with 10 and 8 rock glaciers respectively, and the location of various rock glaciers isolated in massifs of the Eastern Pyrenees (Canigou, Carlit and Puigmal-Carançà).

KEY WORDS: Photo-interpretation, intact rock glaciers, permafrost, high mountain, Pyrenees. 


\section{INTRODUCCIÓN}

A raíz de los trabajos de cartografía geomorfológica a escala 1:25.000 y 1:10.000 que estamos llevando a cabo en la cuenca alta de la Noguera Pallaresa se han identificado pequeños glaciares rocosos «intactos» y probablemente activos en las cabeceras de los circos de Gerber (Pico de Bassiero), Broate (macizo de la Pica d' Estats), Gerri y Baiau (macizo de Monteixo Medacorba). Este hecho nos llevó a plantearnos la realización de un examen exhaustivo a nivel de toda cordillera pirenaica partiendo de los inventarios más recientes de glaciares rocosos (SERRANO et al., 2011) y de la disponibilidad de buena documentación cartográfica (ortofotos color de alta o muy alta resolución) consultable a través de visores cartográficos $2 \mathrm{D}$ y $3 \mathrm{D}$, detectar otros aparatos susceptibles de considerarse como glaciares rocosos potencialmente activos. Las condiciones topoclimáticas y morfológicas que generan la formación y conservación de los glaciares rocosos activos en los Pirineos (situados en fondos de circo por encima de $2.500 \mathrm{~m}$, al pie de paredes bajo cumbres entre 2.800 y $3.200 \mathrm{~m}$ y en orientaciones de componente N) se encuentran también en otros muchos de los altos circos pirenaicos y es de esperar que un análisis sistemático pueda arrojar nuevos resultados ampliando el actual inventario.

Existen dos aspectos destacables que también invitan a iniciar este estudio. En primer lugar, la realización reciente de estudios y cartografía del permafrost de montaña en los Pirineos; en el Macizo de Posets (SERRANO et al., 2001; LUGON et al., 2004; GONZÁLEZ GARCÍA et al., 2012), en el Macizo de la Maladeta (LAMPRE, 1994; GONZÁLEZ GARCÍA et al., 2014) o en ubicaciones marginales como en Peña Telera (CHUECA y JULIÁN, 2004). Por su parte SERRANO et al. (2009) elaboran en un entorno GIS a partir de datos climáticos y de indicadores geomorfológicos un mapa de «Permafrost de montaña en los Pirineos españoles» diferenciando entre zonas sin permafrost, zonas con permafrost posible y zonas con permafrost probable. En el mapa que adjuntan aparecen diversos macizos con permafrost probable o posible de los que no existen citas sobre indicadores geomorfológicos. En nuestro inventario vamos a aportar datos nuevos sobre algunos de ellos (Pica d' Estats, Monteixo-Medacorba, Punta Alta-Colomèrs-Bassiero, Perdiguero-Gourgs Blancs, Monte Perdido, etc.).

A partir de sus datos hemos elaborado la TABLA 1 donde aparecen claramente las franjas altitudinales donde en condiciones morfológicas y topoclimáticas adecuadas pueden generarse glaciares rocosos de origen periglacial como manifestación de la existencia de permafrost o suelo helado. 
En segundo lugar la aceleración del proceso de deglaciación de los glaciares pirenaicos -ver por ejemplo el Informe Programa ERHIN 1984-2008 (ARENILlas et al., 2008) o el libro de J. CAMINS Los 100 últimos glaciares del Sur de Europa- liberando estos grandes espacios a una nueva dinámica geomorfológica periglaciar desde las morrenas de la Pequeña Edad del Hielo (PEH) hasta los frentes actuales o los recuencos superiores libres de hielo pero con neveros, hielo recubierto de derrubios, lóbulos protalud, etc. Dentro de estos procesos se encuentra también la formación de glaciares rocosos de origen glaciogénico ya sea por núcleo de hielo cubierto de derrubios o por morrenas afectadas por flujo.

Tabla 1. Situación altitudinal del permafrost en los Pirineos

\begin{tabular}{cccc}
\hline $\begin{array}{c}\text { Presencia de } \\
\text { Permafrost }\end{array}$ & Orientación Norte & Orientación Sur & $\begin{array}{c}\text { Tipología de } \\
\text { Permafrost }\end{array}$ \\
\hline Posible & $\begin{array}{c}>2.400 \mathrm{~m} \\
2.000 \mathrm{~m}(\mathrm{al} \text { pie de } \\
\text { grandes paredes) }\end{array}$ & $>2.650 \mathrm{~m}$ & Esporádico \\
\hline Probable & $\begin{array}{c}>2.700 \mathrm{~m} \\
>2.630 \mathrm{~m}(\text { caras N.) }\end{array}$ & $>2.800 \mathrm{~m}$ & $\begin{array}{c}\text { Discontinuo o } \\
\text { continuo }\end{array}$ \\
\hline
\end{tabular}

FUENTE: (SERRANO et al., 2009)

\section{GLACIARES ROCOSOS ACTIVOS EN LOS PIRINEOS}

Las primeras referencias sobre glaciares rocosos en los Pirineos se remontan a las décadas de los años 50 y 60 del pasado siglo. SOLÉ SABARÍs (1951) describe estos depósitos, los nombra como «glaciares rocosos» y comenta su presencia en las montañas de Andorra y el alto Segre. BARRÈRE (1952) sin nombrarlos describe como «glacis» o «moraine ordonée» al glaciar rocoso de Bastampé y posteriormente (BARRÈRE, 1953) asocia este tipo de materiales con la presencia de grandes bloques y escasa matriz a «morrenas del Tardiglaciar» y los compara con los actuales aparatos de Pène d' Aragon (Cambalés) y Bastampe (Ardiden). Este autor sitúa en esquemas geomorfológicos varios "glaciers noirs» en los macizos de Balaitús, Vignemale y Néouvielle. ANGELY (1967) describe con detalle al glaciar rocoso de Guerreys pasando este de glaciar a glaciar negro y a glaciar rocoso, presentando unas formas frescas que podrían ser reactivadas.

En la década de los años 80 el interés por los glaciares rocosos genera diversos estudios donde se identifican ya claramente ejemplares de glaciares rocosos activos; Bastampé (CAZENAVE-PIARROT y TIHAY, 1983, 1986), Posets (HAMILTON, 1988), Argualas (SERRANo y RUBio, 1989), Gemelos (AGUdo et al., 1989), y Alba (MARTÍNEZ DE PISÓN, 1989) y un primer «inventario» de estas geoformas incluido en el catálogo de glaciares actuales en los Pirineos 
(MARTÍNEZ DE PISÓN Y ARENILLAS, 1988). En este trabajo se inventarían dos glaciares rocosos activos en el Pirineo español; el glaciar rocoso de Argualas (Macizo de Picos del Infierno) y glaciar norte o de los Gemelos (Macizo de Posets). Unos años más tarde (ARENILLAS et al., 1992) amplían este inventario para el sector español de dos a tres glaciares rocosos (Argualas, Gemelos y Besiberri) pero no incluyen tres más ya conocidos en ese momento (Posets, Cérrez y Alba). Sobre el glaciar rocoso de Besiberri existe una publicación anterior dando cuenta de su actividad (SERRANO et al., 1991).

En los inventarios de glaciares rocosos realizados en esta época (inicio de los años 90) se aborda también la posibilidad de actividad actual o reciente en algunos de los aparatos cartografiados.

MARTí Y SERRAT $(1990,1995)$ con un inventario de más de mil aparatos en el Pirineo catalán considera a la inmensa mayoría de ellos como «glaciares rocosos fósiles» $\mathrm{y}$ 《reduciéndose la posibilidad de actividad a los aparatos situados en los sectores más elevados» en función de factores topoclimáticos favorables. Citan el trabajo de HAMILTON (1988) sobre el glaciar rocoso de Posets y en su artículo de 1995 aportan datos sobre la funcionalidad del glaciar rocoso de Besiberri $\mathrm{N}$ a partir de métodos fotogramétricos. Al respecto indicamos que la fotogrametría es usada por primera vez en el estudio de la dinámica de glaciares rocosos activos en los Pirineos por SANJOSÉ et al., (1992) en el caso concreto del glaciar rocoso de Argualas. MARTí Y SERRAT $(1990,1995)$ comentan también la línea de trabajo que relaciona a algunos glaciares rocosos con los «sistemas glaciares de derrubios» donde un glaciar blanco es paulatinamente recubierto de material detrítico y este construye un glaciar rocoso en su parte frontal. Esta asociación de glaciares rocosos con el glaciarismo actual hace que se incluyan, como hemos comentado anteriormente, a los primeros aparatos cartografiados dentro del catálogo de glaciares pirenaicos (MARTíNEZ De PISÓN y ARENILLAS, 1988).

Por su parte CHUECA $(1989,1991)$ realiza el inventario de los glaciares rocosos situados en el Pirineo aragonés y aplica un análisis estadístico pormenorizado. Establece con los 170 aparatos localizados una clasificación entre «Tipo I - glaciares rocosos activos de origen glaciar» (11 ejemplares); «Tipo II - glaciares rocosos inactivos de origen glaciar» (27 ejemplares) y el «Tipo III - glaciares rocosos inactivos de origen periglaciar» (132 ejemplares). Con respecto a Tipo I comenta que «priman su posible funcionalidad actual y un origen estrechamente ligado al aporte de hielo glaciar» y sitúa en un mapa esquemático a los aparatos detectados, pero comenta su nombre y localización de una forma muy somera «son los ejemplos de Balaitús, Pecico, Argualas, Vignemale, Los Gemelos, Posets o Alba, entre otros de menor entidad» que 
no hemos podido validar. El «Tipo I» definido es a nivel de hipótesis ya que no se demuestra su actividad.

LAMPRE (1998) identifica en el Valle de Vallhibierna (Maladeta) 8 pequeños glaciares rocosos supuestamente funcionales (de la PEH o posteriores) situados en las cotas más elevadas y altitudinalmente muy por encima de otro grupo de glaciares rocosos relictos.

A finales de la década de los años 90 y después de un considerable número de estudios individualizados (incluyendo campañas de mediciones) se inventarían de nuevo los glaciares rocosos activos en los Pirineos (vertiente española y vertiente francesa) acotando la temática y ampliando notablemente el número de estas geoformas activas a 13 ejemplares (SERRANO y AGUDO, 1998; SERRANO et al., 1999).

Más tarde, SERRANO et al. (2011) revisan estos datos incluyendo a un nuevo glaciar rocoso (La Paul) y presentan una visión de conjunto de la dinámica, la evolución y la estructura de los glaciares rocosos activos en los Pirineos. Este trabajo lo tomaremos como punto de partida para nuestro inventario. A los 14 ejemplares localizados vamos a sumarle 4 nuevas geoformas identificadas recientemente para completar el punto de partida (TABLA 2).

Tabla 2. Relación de los glaciares rocosos activos inventariados previamente en los Pirineos

\begin{tabular}{lcl}
\hline Estudio & $N^{o}$ & Nombre y situación por macizos montañosos \\
& & $\begin{array}{l}\text { Cérrez, Argualas (Picos del Infierno) } \\
\text { Cambalès N., Cambalès - Pène d'Aragon, Grand }\end{array}$ \\
SERRANO Y AGUDO (1998) & 13 & $\begin{array}{l}\text { Fache (Marcadau) } \\
\text { Bastampe (Ardiden) } \\
\text { Guerreys (Batoua) } \\
\text { Gemelos, Posets (Posets) } \\
\text { Alba, Maladeta (Maladeta) } \\
\text { Besiberri NW, Besiberri N (1999) }\end{array}$ \\
& +1 & La Paul (Posets) \\
\hline SERRANO et al. (2011) & +3 & $\begin{array}{l}\text { Ardiden (Ardiden) } \\
\text { Mechant, Campbiel (Néouvielle) }\end{array}$ \\
\hline FEUILLET (2010) & +1 & Cotiella (Cotiella) \\
\hline SERRANO Y AGUDO (2004) & 18 & \\
BELMONTE (2014) &
\end{tabular}

FUENTE: Elaboración del autor

La tesis de Feuillet (2010) sitúa en los Pirineos Centrales franceses un total de 8 glaciares rocosos activos y 14 inactivos. El autor mantiene que en toda la cordillera pirenaica el número de glaciares rocosos activos está subestimado y que de inactivos probablemente hay un número importante, pero des- 
conocido hasta la fecha. Por nuestra parte hemos incluido a los nuevos glaciares rocosos activos pero no a los inactivos después de una revisión por fotointerpretación a nivel de criterios fisiográficos y morfométricos (altitud de los frentes, altitud de las cumbres, orientación en algunos aparatos, cobertura vegetal, etc.).

\section{METODOLOGÍA}

Para la identificación e inventario de glaciares rocosos potencialmente activos (GR) en los Pirineos se han realizado las siguientes actividades:

a) Fotointerpretación sobre visores cartográficos en 2D y en 3D: realizada a partir los visores disponibles sobre el área pirenaica (ver TABLA 3). La fotointerpretación se ha realizado directamente con la inspección visual sobre las ortoimágenes aéreas a alta y muy alta resolución (generalmente a $0,5 \mathrm{~m} /$ píxel y en algunas zonas a $0,25 \mathrm{~m} / \mathrm{p}$ íxel) combinando, cuando era posible, la visualización de la imagen en fusión con la cartografía topográfica, la comparativa con ortoimagenes infrarrojo color y la consulta de imágenes históricas o tomadas en años distintos para discriminar mejor la cubierta nival (neveros al inicio de la estación estival).También ha sido de gran interés para aclarar dudas o visualizar mejor las geoformas en su contexto la combinación de las vistas $2 \mathrm{D}$ con las $3 \mathrm{D}$ y el $3 \mathrm{D}$ dinámico. Esta metodología (sobre todo la consulta 3D) ha sido utilizada recientemente para la cartografía de glaciares rocosos, facilitando así la exploración sistemática de áreas de gran extensión territorial por ejemplo en los Andes de Bolivia (RANGECROFT et al., 2014), el Himalaya (SCHMID et al., 2014), en los Alpes franceses (BOBET et al., 2011) o en el mismo Pirineo Oriental (PÉREZ SÁNCHEZ et al., 2013).

Tabla 3. Identificación de los visores cartográficos utilizados en el estudio

\begin{tabular}{|c|c|c|c|}
\hline Nombre del visor & Tipo & Organismo & Zona estudiada \\
\hline $\begin{array}{l}\text { Google Earth } \\
\text { https://www.google.es/earth/index.html }\end{array}$ & $3 \mathrm{D}$ & Google & Toda la cordillera \\
\hline $\begin{array}{l}\text { Iberpix } \\
\text { http://www.ign.es/iberpix2/visor/ }\end{array}$ & $2 \mathrm{D}$ & IGN-España & $\begin{array}{l}\text { Pirineo aragonés y } \\
\text { catalán }\end{array}$ \\
\hline $\begin{array}{l}\text { Géoportail } \\
\text { http://www.geoportail.gouv.fr }\end{array}$ & $2 \mathrm{D}$ & IGN - France & Pirineo francés \\
\hline $\begin{array}{l}\text { Infoterre } \\
\text { http://infoterre.brgm.fr }\end{array}$ & $2 \mathrm{D}$ & BRGM (France) & Pirineo francés \\
\hline $\begin{array}{l}\text { Ide Andorra } \\
\text { www.cartografia.ad/visor-de-mapes } \\
\text { www.ideandorra.ad/geoportal }\end{array}$ & $2 \mathrm{D}$ & Govern d' Andorra & Pirineo andorrano \\
\hline $\begin{array}{l}\text { SITAR Aragón (IDE Aragón) } \\
\text { http://sitar.aragon.es/visores.jsp }\end{array}$ & $\begin{array}{l}2 \mathrm{D} \\
3 \mathrm{D}\end{array}$ & Gobierno de Aragón & Pirineo aragonés \\
\hline $\begin{array}{l}\text { VISSIR - Catalunya } \\
\text { http://www.icc.cat/vissir3 }\end{array}$ & $2 \mathrm{D}$ & ICGC - Catalunya & Pirineo catalán \\
\hline
\end{tabular}

FUENTE: Elaboración del autor 
El estudio se realizó sistemáticamente en todos los macizos pirenaicos con cumbres superiores a los $2.500 \mathrm{~m}$ entre el macizo de Anie-Larra al W. y el de Canigó al E. La fotointerpretación se ha centrado en primer lugar en la diferenciación entre distintas geoformas de interés (glaciar rocoso, glaciar rocoso inicial o lóbulo protalud, morrenas de nevero, morrenas PEH afectadas por flujo) y en segundo lugar en identificar aquellos aspectos que permitan asignar a un ejemplar como glaciar rocoso activo; inspección de los frentes y laterales (fuerte pendiente, presencia de materiales finos,..), ausencia de vegetación, presencia de neveros en el interior o laterales del aparato, enlace activo entre los taludes de la pared y la zona de raíz del glaciar rocoso, la dinámica actual sobre las paredes del circo (actividad de los canchales, canales de aludes, derrubios afectados por flujo), relieve transversal bombeado, estado fresco de arcos transversales y longitudinales y surcos en el interior del aparato.

b) Consulta bibliográfica y fotográfica: la consulta bibliográfica complementaria se centro en la visualización de fotografías históricas y recientes para seguir el proceso de deglaciación de la PEH y la construcción de nuevos GR. En este sentido han sido muy interesantes las obras de CHUECA Y JULIÁN (2002) y de CAMINS (2013).

c) Elaboración de una lista general con todas las geoformas inventariadas por zonas y selección de la lista de potenciales glaciares rocosos activos (a falta de su verificación en campo y/o por teledetección): en una primera selección se descartaron aquellas geoformas que no se consideraron «glaciar rocoso» o «glaciar rocoso inicial» (o lóbulo protalud periglacial) y aquellas otras de pequeñas dimensiones (longitud o anchura $<100 \mathrm{~m}$ ). Por último otras geoformas se descartaron en función de la duda en su atribución. Las principales dudas reportadas que han aparecido son las siguientes:

- Aspecto general no definido

— Dimensiones reducidas

— Lóbulo protalud de reducidas dimensiones

— Origen glaciogénico PEH poco definido

— Duda sobre la funcionalidad en lóbulos superiores de un glaciar rocoso polimórfico (o poligénico)

- Deficiente calidad de la imagen (poco definida o contrastada, deficiente observación del talud y del enlace vertiente - raíz, presencia excesiva de nieve, etc.) 
Aunque mantenemos en el estudio la denominación de «glaciares rocosos potencialmente activos», solo con la identificación por fotointerpretación y bajo criterios estrictamente morfológicos (fisiográficos) los GR que ahora inventariamos debemos considerarlos, según la clasificación de BARSH (1996) como «intact rock glaciers», agrupando en esta categoría tanto a los «active rock glaciers» como a los «inactive rock glaciers» (con presencia de hielo en su interior y con nula o poca dinámica), ambos indicadores de presencia de permafrost en la alta montaña. La agrupación anterior ha sido adoptada por la mayoría de los recientes inventarios regionales de glaciares rocosos diferenciando a los «intact rock glaciers» de los «relict o fossil rock glaciers», como por ejemplo en Noruega (LILLEOREN y ETZEMÜLLER, 2011), en los Alpes austríacos (Kellerer-PIRKLBAUER et al., 2012), en los Alpes italianos (BARONI et al., 2004), o en los Andes argentinos (MARTINI et al., 2013).

En la TABLA 4 se indican el total de geoformas inventariadas, su zona geográfica, las incluidas en inventarios previos y finalmente las seleccionadas para incluir en el nuevo inventario.

Tabla 4. Datos generales de los glaciares rocosos y geoformas relacionadas inventariadas

\begin{tabular}{|c|c|c|c|c|}
\hline Zona & $\begin{array}{l}\text { Total Geoformas } \\
\text { identificadas }\end{array}$ & $\begin{array}{l}\text { GR Inventario } \\
\text { previo (2011) }\end{array}$ & $\begin{array}{l}\text { GR Dudo- } \\
\quad \text { sos }\end{array}$ & $\begin{array}{l}\text { Nuevos GR potencia- } \\
\text { les activos (2015) }\end{array}$ \\
\hline $\begin{array}{l}\text { Pirineo meridional (Es- } \\
\text { paña y Andorra) }\end{array}$ & 139 & 10 & 84 & 45 \\
\hline $\begin{array}{ll}\text { Pirineo } & \text { septentrional } \\
\text { (Francia) } & \end{array}$ & 83 & 8 & 51 & 24 \\
\hline Total: & 222 & 18 & 135 & 69 \\
\hline
\end{tabular}

FUENTE: Elaboración del autor

d) Preparación de una tabla resumen (ver TABLA 5) para situar, parametrizar y clasificar a los GR seleccionados (tanto los inventariados anteriormente como los nuevos identificados): Mediante la consulta a inventarios recientes de glaciares rocosos (tanto fósiles como activos/inactivos) en varias zonas de los Alpes y Pirineos (BARONI et al., 2004; MONNIER, 2006; SCAPOZZA, 2008; KELlERER-PirKlBAUer et al., 2012; KRAINER y RIBIS, 2012; PÉREZ SÁNCHEZ et al., 2013) hemos preparado una ficha extensa con 34 parámetros distintos (algunos de ellos a documentar en una posterior fase de trabajo de campo) que se agrupan en:

— Posición (6 elementos): nombre, macizo, cuenca, coordenadas, etc.

- Morfometría (16 elementos): altitud raíz, altitud del frente, altitud cumbre, desnivel, orientación, longitud, anchura, índice de elongación, superficie, etc. 
- Características (10 elementos): localización geomorfológica, morfología, litología, tipo; aquí se han conservado la clasificación de SERRANO et al. (2011), en $\mathrm{Pt}$-glaciar rocoso de talud periglacial y Ggd- glaciar rocoso de derrubios glaciogénicos. Incluye 6 elementos a validar en campo (presencia de fuentes, grado de colonización vegetal/líquenes, origen del hielo, origen de los derrubios, descripción detallada de la superficie y los laterales del aparato).

— Datos adicionales (2 elementos): base cartográfica utilizada y referencias bibliográficas.

e) Realización de un primer análisis estadístico y una caracterización de «tipologías» de GR potencialmente activos sumando a los nuevos aparatos detectados a los ya incluidos en inventarios previos.

\section{RESULTADOS}

En este capítulo se describen los principales resultados del estudio en esta fase de inventario. Las referencias a GR concretos que aparecen en el texto vienen acompañados de un número entre paréntesis que se corresponde con el número identificativo de la tabla general de glaciares rocosos (TABLA 5).

\section{IV.1. Análisis regional}

Destacamos las siguientes consideraciones:

1. A los 9 macizos pirenaicos con GR activos conocidos (Picos del Infierno, Marcadau, Ardiden, Néovielle-Pic Long, Batoua, Cotiella, Posets, Maladeta y Besiberri) se le añaden los siguientes 15 nuevos macizos (de W a E): Balaitús, Tendeñera, Vignemale, Monte Perdido, Bachimala, Eriste, PerdigueroGourgs Blancs, Punta Alta-Colomèrs, Certascan, Monteixo-Medacorba, Estanyó, Carlit, Puigmal-Costabona y Canigó.

2. A los 18 GR inventariados previamente se le suman un total de 69 nuevos aparatos «potencialmente activos» distribuidos por los distintos macizos tal y como aparecen en la TABLA 6. De estos 69 GR, 22 se sitúan en macizos identificados previamente y el resto, 47 GR se ubican en los nuevos macizos que reportamos en este estudio.

3. En el Pirineo Central de Lleida y zonas limítrofes encontramos una importante concentración de GR (23 aparatos) situados en 5 macizos. Algunos de estos GR presentan una gran extensión y aspecto externo que puede evidenciar su actividad.

4. El inventario se extiende también hacia el Pirineo Oriental donde a favor de unas condiciones topoclimáticas muy concretas encontramos varios GR en 
el Carlit (83), en el Canigó (87) y en algunas localizaciones en Puigmal-Carança $(84,85$ y 86$)$ con aspecto externo diferenciable (frente y arcos externos abruptos, ausencia de vegetación, apariencia de finos en los frentes) del resto de glaciares relictos que se encuentran en el macizo.

Tabla 6. Relación de macizos pirenaicos con glaciares rocosos activos y potencialmente activos ${ }^{(*)}$

\begin{tabular}{|c|c|c|c|c|c|}
\hline$N^{o}$ & Macizo & $\begin{array}{c}\text { Altitud } \\
\text { máxima }(\mathrm{m})\end{array}$ & $\begin{array}{c}\text { GR activos } \\
\text { (2011) }\end{array}$ & $\begin{array}{c}\text { GR nuevos } \\
\text { potenciales (2016) }\end{array}$ & $\begin{array}{l}N^{\circ} G R \\
\text { (total) }\end{array}$ \\
\hline 1 & Balaitús & 3.146 & 0 & 1 & 1 \\
\hline 2 & Marcadau & 3.005 & 3 & 0 & 3 \\
\hline 3 & Picos del Infierno & 3.081 & 2 & 1 & 3 \\
\hline 4 & Tendeñera & 2.845 & 0 & 1 & 1 \\
\hline 5 & Vignemale & 3.298 & 0 & 2 & 2 \\
\hline 6 & Ardiden & 2.988 & 2 & 1 & 3 \\
\hline 7 & Monte Perdido & 3.348 & 0 & 3 & 3 \\
\hline 8 & Néouvielle-Pic Long & 3.192 & 2 & 4 & 6 \\
\hline 9 & Batoua & 3.034 & 1 & 1 & 2 \\
\hline 10 & Bachimala & 3.174 & 0 & 1 & 1 \\
\hline 11 & Cotiella & 2.912 & 1 & 0 & 1 \\
\hline 12 & Eriste & 3.056 & 0 & 2 & 2 \\
\hline 13 & Posets & 3.369 & 3 & 0 & 3 \\
\hline 14 & Perdiguero-Gourgs B. & 3.222 & 0 & 10 & 10 \\
\hline 15 & Maladeta & 3.404 & 2 & 10 & 12 \\
\hline 16 & Besiberri-Montardo & 3.029 & 2 & 5 & 7 \\
\hline 17 & Punta Alta-Colomèrs & 3.014 & 0 & 8 & 8 \\
\hline 18 & Certascan & 2.853 & 0 & 1 & 1 \\
\hline 19 & Pica d' Estats & 3.143 & 0 & 4 & 4 \\
\hline 20 & Monteixo-Medacorba & 2.944 & 0 & 5 & 5 \\
\hline 21 & Estanyó & 2.915 & 0 & 4 & 4 \\
\hline 22 & Carlit & 2.921 & 0 & 1 & 1 \\
\hline 23 & Puigmal-Carançà & 2.909 & 0 & 3 & 3 \\
\hline 24 & Canigó & 2.784 & 0 & 1 & 1 \\
\hline \multicolumn{3}{|c|}{ Total } & 18 & 69 & 87 \\
\hline
\end{tabular}

(*) Los macizos incluidos en los inventarios anteriores aparecen resaltados. FUENTE: Elaboración del autor

5. Volviendo al global del inventario también cabe destacar a 2 de los nuevos macizos reportados con una importante cantidad de GR; el de PerdigueroGourgs Blancs y el de Punta Alta-Colomèrs con 10 y 8 GR respectivamente.

6. En el grupo de 135 geoformas que no hemos incluido en el inventario se encuentran algunas zonas y aparatos concretos que merecerán a futuro una revisión como por ejemplo el macizo de Panticosa (GR Peña de Xuans), el de Subenuix-Peguera (GR de Saburó y GR de Mainera), el de Marcadau (GR Petit Pic d' Arratille), la región de Estom-Soubiran (Pic de la Sède- Pic de Labas) o las morrenas de los glaciares de los Portillones (Maladeta). 


\section{IV.2. Comparativa del inventario previo con el inventario actual}

En la TABLA 7 se muestra una comparativa entre los datos morfométricos más relevantes entre los inventarios previos y el inventario realizado en este estudio.

1. Las medias obtenidas tanto en la altura de cumbres como en las alturas de las raíces y los frentes de los glaciares es muy parecida, no así las mínimas. Estamos ampliando el mismo «nicho» morfológico y topoclimático de los 18 GR activos a un importante número de nuevas localizaciones.

2. Pero estos datos globales esconden la presencia de un grupo importante de GR (el 32,2\%) que situándose bajo cumbres con alturas por debajo de la altura mínima de los inventarios anteriores $(2.912 \mathrm{~m})$, presentan unas medias parciales unos 100 metros más bajas que el conjunto en la altura de las cumbres, en la altura de la raíz y en la altura mínima de los frentes; 25 de los 28 GR de este subgrupo son glaciares rocosos de talud periglaciar.

3. La comparativa entre los dos inventarios por lo que respecta a longitud (longitud total del GR), anchura y superficie muestra claramente que el nuevo inventario incluye un número importante de aparatos de reducidas dimensiones. Se ha detectado pues un grupo significativo de GR pequeños (glaciar rocoso inicial, lóbulo protalud) con posible actividad.

Tabla 7. Comparativa de los datos principales sobre glaciares rocosos entre el inventario inicial y el actual

\begin{tabular}{lcccc}
\hline \multirow{2}{*}{ Características (m.) } & \multicolumn{2}{c}{$\begin{array}{c}\text { Inventarios previos (2011) } \\
\text { GR activos (18) }\end{array}$} & \multicolumn{2}{c}{$\begin{array}{c}\text { Inventario actual (2016) } \\
\end{array}$} \\
\cline { 2 - 5 } & Media & Min. - Máx. & Media & Min. - Máx. \\
\hline Altura cumbres & 3.053 & $2.912-3.375$ & 2.982 & $2.750-3.375$ \\
\hline Altura raíz GR & 2.793 & $2.566-3.060$ & 2.755 & $2.483-3.075$ \\
\hline Altura base frente GR & 2.670 & $2.450-2.965$ & 2.674 & $2.440-3.025$ \\
\hline Altura de la pared dominante & 260 & $72-445$ & 227 & $72-455$ \\
\hline Longitud máxima & 376 & $123-794$ & 220 & $45-794$ \\
\hline Anchura & 169 & $68-443$ & 141 & $45-443$ \\
\hline Superficie $\left(\mathrm{m}^{2}\right)$ & 57.745 & & 27.729 &
\end{tabular}

FUENTE: Elaboración del autor

\section{IV.3. Orientación}

En la TABLA 8 se muestra claramente el dominio de las orientaciones de componente Norte (N, NE y NW) en la ubicación de los GR activos + GR nuevos ( $82,7 \%$ y 72 de los 87 ejemplares). 


\section{IV.4. Altura mínima de los frentes de los glaciares rocosos}

1. Las franjas altitudinales de $2.500-2.600 \mathrm{~m}$ y $2.600-2.700 \mathrm{~m}$ son las que concentran más de la mitad de los GR (57, 5\%, 50 aparatos). Su altitud media (2597 m) se sitúa en el límite inferior del permafrost discontinuo.

Tabla 8. Distribución de los glaciares rocosos según su orientación

\begin{tabular}{crr}
\hline Orientación & $N^{\circ}$ & $\%$ \\
\hline $\mathrm{N}$ & 35 & $40,2 \%$ \\
\hline $\mathrm{NE}$ & 15 & $17,2 \%$ \\
\hline $\mathrm{E}$ & 3 & $3,4 \%$ \\
\hline $\mathrm{SE}$ & 1 & $1,1 \%$ \\
\hline $\mathrm{S}$ & 2 & $2,3 \%$ \\
\hline $\mathrm{SW}$ & 5 & $5,7 \%$ \\
\hline $\mathrm{W}$ & 4 & $4,6 \%$ \\
\hline $\mathrm{NW}$ & 22 & $25,3 \%$ \\
\hline Total: & 87 & $100,0 \%$
\end{tabular}

FUENTE: Elaboración del autor

2. Solo un el 4,6\% de los GR (4 aparatos) sitúan sus frentes en cotas inferiores a $2.500 \mathrm{~m}$ y únicamente en orientaciones de componente $\mathrm{N}$ y generalmente bajo paredes de circo de gran amplitud. Pertenecen a este grupo límite los GR de Tendeñera (8), Ardiden-Gran Lac (11), Cotiella (26) y Canigó (87).

Tabla 9. Distribución de los glaciares rocosos según franjas altitudinales y orientación

\begin{tabular}{|c|c|c|c|c|c|}
\hline \multicolumn{2}{|c|}{$\begin{array}{c}\text { Altura minima }(\mathrm{m}) \\
y \%(\text { frente } G R)\end{array}$} & \multirow{2}{*}{$\begin{array}{r}\text { Global } \\
4\end{array}$} & \multirow{2}{*}{$\begin{array}{r}\text { Orientación } \\
N \\
4\end{array}$} & \multirow{2}{*}{$\begin{array}{r}\text { Orientación } \\
S \\
0\end{array}$} & \multirow{2}{*}{$\begin{array}{r}\text { Orientación } \\
E / W \\
0\end{array}$} \\
\hline $4,6 \%$ & $<2.500$ & & & & \\
\hline $32,2 \%$ & $2.501-2.600$ & 28 & 27 & 0 & 1 \\
\hline $25,3 \%$ & $2.601-2.700$ & 22 & 21 & 1 & 0 \\
\hline $17,2 \%$ & $2.701-2.800$ & 15 & 11 & 2 & 2 \\
\hline $13,8 \%$ & $2.801-2.900$ & 12 & 6 & 4 & 2 \\
\hline $5,7 \%$ & $2.901-3.000$ & 5 & 3 & 1 & 1 \\
\hline $1,1 \%$ & $3.001-3.100$ & 1 & 0 & 0 & 1 \\
\hline \multirow[t]{2}{*}{$100 \%$} & Total & 87 & 72 & 8 & 7 \\
\hline & & & $82,8 \%$ & $9,2 \%$ & $8,0 \%$ \\
\hline
\end{tabular}

FUENTE: Elaboración del autor

3. Prácticamente hasta los $2.700 \mathrm{~m}$ no se encuentran frentes de GR en orientaciones de componente $\mathrm{S}$ ( 8 aparatos). Su altura media se sitúa en $2.797 \mathrm{~m}$ y se sitúan bajo cumbres de más de $3000 \mathrm{~m}$ y con paredes de circo con desnivel importante (media de $180 \mathrm{~m}$ ). Destacan por su extensión los GR de Pico de Alba-Cregüeña (46) en la Maladeta y de Pico Forqueta-Bagueña (27) en el macizo de Eriste. 
4. Las franjas altitudinales superiores $(>2.900 \mathrm{~m})$ presentan pocos ejemplares (6 aparatos). Situados bajo las cumbres más altas $(>3.100 \mathrm{~m})$ y en zonas recientemente deglaciadas de la $\mathrm{PEH}$ tienen un origen tanto de talud periglaciar ( 3 ejemplares) como de derrubios glaciares ( 3 ejemplares). A los GR conocidos de Posets (29), Alba-1 (42), Maladeta Occd-1 (43) y Campbieil (17) le sumamos las nuevas localizaciones de Russell Sur (51) y Cilindro de Marboré (15).

\section{IV.5. Longitud máxima}

En el GRÁFICO 1 se muestran los datos relativos a la longitud máxima alcanzada por los GR del nuevo inventario.

Gráfico 1. Distribución de los glaciares rocosos según su longitud máxima

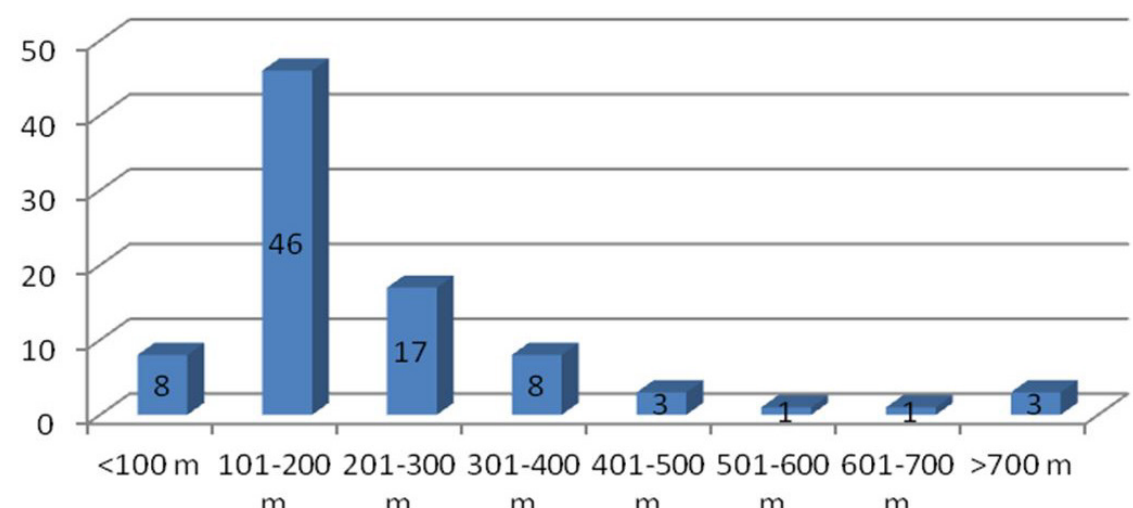

$\mathrm{m} \quad \mathrm{m} \quad \mathrm{m} \quad \mathrm{m} \quad \mathrm{m} \quad \mathrm{m}$

FUENTE: Elaboración del autor

1. La inmensa mayoría de los GR pertenece al grupo con longitudes comprendidas entre los 100 y $200 \mathrm{~m}$ (46 ejemplares). Si sumamos los dos primeros grupos ( $<100 \mathrm{~m}$ y 100-200 m) obtenemos $54 \mathrm{GR}$ (el 62,1\% del total). Queda claro pues el dominio de las dimensiones reducidas en los nuevos GR identificados como GR con posible actividad. Para completar este punto comentar que del inventario previo, todos los 18 GR tienen una longitud superior a los $200 \mathrm{~m}$.

2. Los grandes GR con longitudes superiores a los $300 \mathrm{~m}$ forman un grupo reducido de 16 aparatos $(18,4 \%$ ) que incluye a 10 GR inventariados previamente y 6 GR nuevos de grandes dimensiones; Pic d'Aygues Cluses (32), Pico de Alba-2 (44), Pico Alba-Cregüeña (46), Punta Harlé-1 (57), Comalesbienes (61) y Comalespales-Coll de Colieto (63). 


\section{IV.6. Superficie}

Para ordenar los datos relativos a la extensión de los GR adjuntamos una tabla con la distribución por intervalos de extensión de los GR con la información asociada del número de ejemplares, la superficie acumulada y los respectivos porcentajes para cada clase.

Tabla 10. Distribución de los glaciares rocosos según su superficie

\begin{tabular}{crrrr}
\hline Superficie $\left(\mathrm{m}^{2}\right)$ & $N^{o}$ & $\%$ & $\begin{array}{r}\text { Superficie } \\
\text { acumulada }\left(\mathrm{m}^{2}\right)\end{array}$ & $\begin{array}{r}\% \text { por grupo de } \\
\text { superficie }\end{array}$ \\
\hline$<5.000$ & 1 & $1,15 \%$ & 3.250 & $0,13 \%$ \\
$5-10.000$ & 22 & $25,29 \%$ & 168.816 & $7,00 \%$ \\
$10-20.000$ & 23 & $26,44 \%$ & 300.617 & $12,46 \%$ \\
$20-40.000$ & 26 & $29,89 \%$ & 669.649 & $27,76 \%$ \\
$40-80.000$ & 6 & $6,90 \%$ & 307.259 & $12,74 \%$ \\
$>80.000$ & 9 & $10,34 \%$ & 962.838 & $39,91 \%$ \\
& 87 & $100 \%$ & 2.412 .429 & $100 \%$ \\
\hline
\end{tabular}

FUENTE: Elaboración del autor

Gráfico 2. Superficie acumulada de los glaciares rocosos en función de su orientación

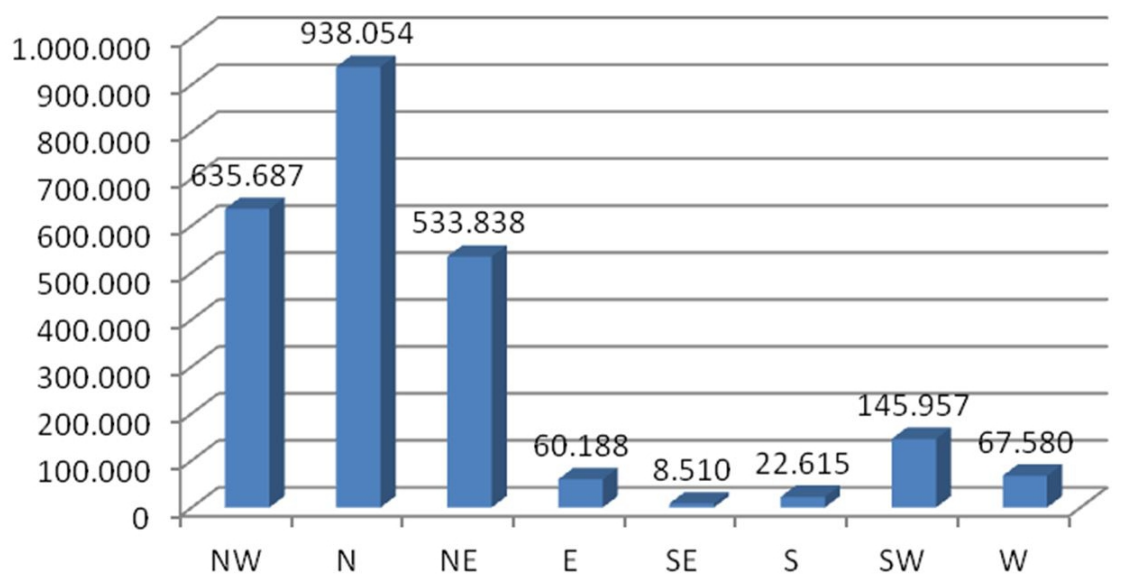

FUENTE: Elaboración del autor

Completamos este punto con el GRÁfICO 2 en el que se representan las superficies acumuladas por orientación de la totalidad de los 87 GR inventariados. Se muestra gráficamente el dominio absoluto, como en el análisis de otros parámetros, de las orientaciones con componente N. Estas suman un total de 72 GR $(82,8 \%)$ y una extensión acumulada que representa casi el $90 \%$ $(87,4 \%)$ del total. 


\section{IV.7. Clasificación y Tipologia}

De las tres clasificaciones básicas de los GR comentadas en la síntesis de SERRANO (2014); geometría, origen de los materiales y del hielo y estado de actividad, vamos centrarnos en la que hace referencias al origen de los materiales que construyen los GR. En la clasificación genética se identifican dos tipologías; la de talud periglaciar - Pt (talus rock glaciers) y la de derrubios glaciogénicos - Ggd (debris rock glaciers).

Esta clasificación fue utilizada en el inventario de SERRANO et al. (2011) y vamos a mantenerla. Hemos introducido una subdivisión en cada uno de los dos tipos básicos y junto a otros parámetros morfométricos se ha realizado la siguiente tabla donde se definen 5 tipologías básicas de GR. La tabla incluye datos generales sobre el número de GR, la superficie cubierta, las características y algunos ejemplos para cada «tipo definido» de GR (con ejemplos tanto del inventario anterior como del actual).

Tanto los datos de la clasificación genética como los de la clasificación morfológica de los GR aparecen en la ficha general (ver TABLA 5). Con respecto a la clasificación morfológica se diferencian los siguientes tipos; lóbulo protalud (protalus lobe), lóbulo, lengua y complejo.

En el inventario se incluyen en las dos tipologías de Ggd (origen glaciogénico) un total de 25 aparatos, 8 inventariados previamente y 17 nuevos. En este grupo se ha optado por incluir una serie de geoformas cuya asignación final a GR deberá realizarse después de un trabajo de campo minucioso y/o mediante la aplicación de técnicas de medición (terrestres o por teledetección) para validar su funcionalidad. Aún con la duda sobre varios de ellos hemos optado por incluirlos ya que representan una variedad de GR que de validarse estará en relación directa con el reciente proceso de retroceso y fusión de los glaciares construidos durante la PEH y por tanto mostrarían bien la transición de glaciar a glaciar cubierto y/o a glaciar rocoso realizada en un corto periodo temporal. A continuación y a modo de ejemplo anotamos observaciones sobre dos ejemplares:

1. GR Cilindro de Marboré-Goriz (15): Aparece como un glaciar perfectamente delimitado en el mapa de Schrader (1874). Comentario y cartografía como «helero residual del Cilindro» (MARTínEZ DE PISÓN Y ARENILLAS, 1988). «Los restos constatables en los años 80 han desaparecido» (ARENILLAS et al., 1992). Cartografía de las morrenas en el Mapa geomorfológico del Parque Nacional de Ordesa y Monte Perdido (GARCÍA RUIZ Y MARTí BONO, 2001). Por fotointerpretación se aprecia un potente volumen de material morrénico con un límite fronto-lateral abrupto $(25 \mathrm{~m})$. La acumulación presenta 
pequeñas depresiones y de la pared del Cilindro se aprecian canchales activos afectados por flujo, desprendimientos y neveros situados en contacto con la raíz de la acumulación. Clasificación Ggd-1.

Tabla 11. Tipologías de glaciares rocosos activos, características generales y

\begin{tabular}{|c|c|c|c|}
\hline Tipo & $N^{o}$ & $\begin{array}{c}\text { Superficie } \\
\left(\mathrm{m}^{2}\right)\end{array}$ & Características \\
\hline Pt-1 & $\begin{array}{c}25 \\
(28,7 \%)\end{array}$ & $\begin{array}{c}226.591 \\
(9,4 \%)\end{array}$ & $\begin{array}{l}\text { Lóbulos Protalud } \\
\text { Superficie media : } 9000 \mathrm{~m}^{2}\left(\text { entre } 5000 \text { y } 15.000 \mathrm{~m}^{2}\right) \\
\text { Longitud media: } 115 \mathrm{~m} \mathrm{(máxima} 150 \mathrm{~m}) \\
\text { GR-EP: sin GR inventariados (diversos autores no consideran a } \\
\text { los lóbulos protalud como GR verdaderos y por tanto todo y su } \\
\text { estudio y cartografia no se han inventariado en los Pirineos como } \\
\text { tales) } \\
\text { GR-EA: } 47 \text {-Estatats-Cregüeña, 69-Montabone, 70-Broate W. }\end{array}$ \\
\hline Pt-2 & $\begin{array}{c}23 \\
(26,4 \%)\end{array}$ & $\begin{array}{l}396.674 \\
(16,4 \%)\end{array}$ & $\begin{array}{l}\text { GR de pequeñas dimensiones pero con varios arcos, surcos y la- } \\
\text { terales y frente bien delimitados } \\
\text { Superficie inferior a } 25.000 \mathrm{~m}^{2}\left(\text { media } 17.250 \mathrm{~m}^{2}\right) \\
\text { Longitud media: } 184 \mathrm{~m}(\text { máxima } 262 \mathrm{~m}) \\
\text { GR-EP: 26-Cotiella, 17-Campbieil, } 43 \text {-Maladeta Occd.-1 } \\
\text { GR-EA: 10-Crète de la Hourquette, 25-Gran Bachimala }\end{array}$ \\
\hline $\mathrm{Pt}-3$ & $\begin{array}{c}14 \\
(16,1 \%)\end{array}$ & $\begin{array}{l}704.545 \\
(29,2 \%)\end{array}$ & $\begin{array}{l}\text { GR de grandes dimensiones. Morfologías nítidas } \\
\text { Superficies entre } 25.000 \text { y } 100.000 \mathrm{~m}^{2}\left(\text { media } 50.325 \mathrm{~m}^{2}\right) \\
\text { Longitud media: } 310 \mathrm{~m} \text { (máxima } 508 \mathrm{~m}) \\
\text { GR-EP:3-Cambalès N, 7-Argualas, 23-Guerreys } \\
\text { GR-EA:32 Aygues Cluses, 61-Comalesbienes, 64-Contraix }\end{array}$ \\
\hline Ggd-1 & $\begin{array}{c}15 \\
(17,2 \%)\end{array}$ & $\begin{array}{l}882.093 \\
(36,6 \%)\end{array}$ & $\begin{array}{l}\text { GR derivados de la transición glaciar-glaciar negro- GR } \\
\text { Vinculados mayoritariamente a la PEH y a la fusión reciente de } \\
\text { glaciares y heleros } \\
\text { Dimensiones variables (en longitud y superficie) } \\
\text { Necesaria validación en campo para su atribución definitiva } \\
\text { GR-EP:11-Ardiden-Lac Grand, 31-Gemelos, } 55 \text {-Besiberri NW } \\
\text { GR-EA:41-Remuñé, 63-Comalespales, 87-Canigó }\end{array}$ \\
\hline Ggd-2 & $\begin{array}{c}10 \\
(11,5 \%)\end{array}$ & $\begin{array}{c}202.526 \\
(8,4 \%)\end{array}$ & $\begin{array}{l}\text { Variante del tipo anterior } \\
\text { GR generadas a partir de morrenas frontales o laterales PEH afec- } \\
\text { tadas por flujo (permafrost) } \\
\text { Necesaria validación en campo para su atribución definitiva } \\
\text { GR-EP:29-Posets, 30- La Paul } \\
\text { GR-EA:16-Collado de Astazú, 20-Bugarret-Lac Tourrat }\end{array}$ \\
\hline 5 & 87 & 2.412 .429 & GR-EP (inventario previo); GR-EA (nuevos GR inventariados) \\
\hline
\end{tabular}

FUENTE: Elaboración del autor

2. GR Collado de Astazú-Marboré (16): Todo el sector está ocupado por glaciares en el mapa de SCHRADER (1874) formando un continuo en el Circo de Marboré desde la base del Monte Perdido hasta la vertical del Pico de Marboré. Cartografía de las morrenas en el Mapa geomorfológico del Parque Nacional de Ordesa y Monte Perdido (GARCíA RUIZ Y MARTí BONO, 2001) sin asignación cronológica. En GARCÍA RUIZ et al. (2014) incluyen en un mapa las morrenas y otros depósitos en el Circo de Marboré y la acumulación inventariada aparece como "supuesto glaciar rocoso» situado en contacto 
fronto-lateral con morrenas holocenas (anteriores a las de la PEH). En la acumulación se observan varios grandes lóbulos procedentes de una zona de raíz formada por morrenas de fondo donde se aprecian alineaciones direccionales frecuentes en otras localidades alpinas y pirenaicas (DELALOYE et al., 2003). Clasificación Ggd-2.

\section{CONCLUSIONES}

1. La fotointerpretación mediante visores cartográficos 2D y 3D se ha mostrado como una potente herramienta para la identificación e inventario de potenciales glaciares rocosos activos. Permite una «exploración» detallada de grandes conjuntos territoriales (en este caso la totalidad de la cordillera pirenaica). La existencia en todo el territorio estudiado de coberturas de ortofoto color de alta resolución $(0,5-0,25 \mathrm{~m} /$ píxel $)$ permite un análisis detallado de estas geoformas. La superposición de diversas capas cartográficas temporales y la visualización dinámica en 3D prestan un gran apoyo a las tareas de fotointerpretación geomorfológica.

2. Se han seleccionado un total de 69 nuevos GR potencialmente activos, englobando en esta definición y a falta de su validación final, a los glaciares rocosos activos como a los inactivos agrupados dentro del término de «intact rock glaciers». Junto a los 18 aparatos ya censados situamos en este nuevo inventario a un total de $87 \mathrm{GR}$. Algunos geoformas dudosas del inventario general inicial no incluidas actualmente deberán verificarme por otros métodos. Todas los nuevos aparatos ocupan el mismo «nicho topoclimático» que el grupo de GR inventariado previamente. Se ha ampliado el número de altos macizos con GR potencialmente activos y en algunos casos las cotas inferiores de los mismos o la altura máxima de las cumbres principales que los cobijan se han reducido sensiblemente.

3. El conjunto de los 87 GR se ha agrupado en 5 tipologías; 3 pertenecientes a glaciares rocosos de talud periglaciar y 2 a glaciares rocosos de derrubios glaciogénicos. A destacar el grupo de GR (Pt-1) de reducidas dimensiones (longitud o anchura superior a $100 \mathrm{~m}$.) correspondiente a glaciares rocosos iniciales o lóbulos protalud no incluidos en los primeros inventarios. En cuanto a extensión pasamos de $1 \mathrm{Km}^{2}$ (para 13 GR del inventario previo) a $2,4 \mathrm{Km}^{2}$ (en el inventario actual con los $87 \mathrm{GR}$ )

4. La continuidad de este estudio regional en una segunda fase debería pasar por el avance en dos líneas de trabajo: a) la verificación en campo y la cartografía geomorfológica detallada de una selección de los nuevos GR localizados; b) la monitorización por teledetección mediante tecnología de interferometria radar diferencial (DinSAR) permitiría de una forma rápida y para todo 
el conjunto de la cordillera la verificación del movimiento en los GR, su zonificación y la cuantificación de la velocidad de desplazamiento (en mm/año). Recientes experiencias en los Alpes y en otras cordilleras avalan el uso de esta tecnología (ECHEARD, 2014; LIU et al., 2013).

\section{BIBLIOGRAFIA}

Agudo, C.; Serrano, E.; MartíneZ de Pisón, E. (1989): «El glaciar rocoso activo de Los Gemelos en el macizo de Posets (Pirineo aragonés)». Cuaternario y geomorfología, 3 (1-4), 83-92.

Angely, G. (1967): «Anciens glaciers dans l'est des Pyrénées centrales». Revue Geographique Pyrénées Sud-Ouest, 38(1), 5-28.

Arenillas, M.; Martínez, R.; Martínez De Pisón, E. (1992): «El estado de los glaciares españoles en 1991». Eria, 28, 176-182.

ARENILlAS, M.; COBOS, G.; NAVARRO, J. (2008): «Los glaciares españoles, evolución reciente y situación actual», en Datos sobre la nieve y los glaciares en las cordilleras españolas. El programa ERHIN 1984-2008. Madrid. Ministerio de Medio Ambiente y Medio Rural y Marino, 93-168.

BARONI, C.; CARTON, A.; SePPI, R. (2004): «Distribution and Behaviour of Rock Glaciers in the Adamello-Presanella Massif (Italian Alps)». Permafrost and Periglacial Processes, 15, 243-259.

BARRÈRE, P. (1952): «Le relief des massifs granitiques du Néouvielle,de Cauterets et de Panticosa». Revue Geographique Pyrénées Sud-Ouest, 23, 69-98.

BARRÈRE, P. (1953): «Équilibre glaciaire actuel et quaternaire dans l'Ouest des Pyrénées centrales». Revue Geographique Pyrénées Sud-Ouest, 24 (2), 116-134.

BARSH, D. (1996): Rock glaciers. Indicators for the present and former geoecology in high mountain environment. Berlin, Springer Verlag.

Belmonte, A. (2014): Geomorfología del macizo de Cotiella (Pirineo oscense): cartografía, evolución paleoambiental y dinámica actual. Tesis Doctoral. Universidad de Zaragoza (inédita).

Bouvet, P.; Charvet, R.; Riguidel, A. (2011): Les glaciers-rocheux dans les Hautes-Alpes : Inventaire, cartographie et risques associés. Gap. Office National des Forets, Service de Restauration des Terrains en Montagne des Hautes-Alpes.

CAmins, J. (2013): Los 100 últimos glaciares del sur de Europa. Igualada, Besa \& Keops, S.L.

CAZENAVE-PIARROT, F.; TIHAY, J.P. (1983): «Eboulis, formations morainiques et glaciers rocheux dans le massif de l' Ardiden (Pyrenees Centrales)» en, Eboulis et environnement géographique passé et actuel. Paris, A.G.F., Publ. Centre Géogr. Phys., 121-138.

CaZenave-Piarrot, F. ; Tihay, J.P. (1986): «Glaciers rocheux dans les Pyrénées Centrales et Occidentales», en Communication a la Societé Hydrotechnique de France (section Glaciologie), Paris.

CHUECA, J. (1989): «Características de los glaciares rocosos del área meridional del batolito de Panticosa (Pirineo Oscense)». Geographicalia, 26, 61-74. 
ChueCA, J. (1991): «Aplicación de métodos de análisis factorial en el establecimiento de una tipología de los glaciares rocosos del Pirineo central oscense». Cuaternario y Geomorfología, 5, 27-43.

ChueCA, J.; Julián, A. (2002): «Los glaciares pirenaicos aragoneses: Estudio de su evolución desde el final de la pequeña edad del hielo hasta la actualidad a través de documentación fotográfica (1880-1990)». Boletín Glaciológico Aragonés (número extraordinario).

ChueCA, J.; Julián, A. (2004): «Determinación de la existencia de permafrost en la Sierra de Telera (Pirineo central español), a partir de sondeos eléctricos verticales y mediciones BTS». Boletín de la Real Sociedad Española de Historia Natural, $99,65-74$.

Delaloye, R.; LAmBiel, C.; Reynard, E.; LugON, R. (2003): «Réponse du pergelisol à la avancée glaciaire du petit age glaciaire : quelques exemples alpins et pyrénéens». Environnements périglaciaires, 10, 46-65.

ECHELARD, T. (2014) : Contribution à l'étude de la cinématique des glaciers rocheux dans les Alpes françaises par interférométrie radar différentielle (D-InSAR). Thèse de Doctorat, Université de Grenoble.

Feuillet, T. (2010) : Les formes périglaciaires dans les Pyrénées Centrales Françaises: Analyse Spatiale, Chronologique et valorisation. Thèse de Doctorat, Institut de Géographie et d' Aménagement Régional (IGARUN), Université de Nantes.

GARCÍA-RUIZ, J.M.; MARTí BONO, C.E., (2001): Mapa geomorfológico del Parque Nacional de Ordesa y Monte Perdido. Madrid, Organismo Autónomo de Parques Nacionales (OAPN).

García-Ruiz, J.M.; PALACIOS, D.; De ANDRÉS, N.; VAlero GARCÉS, B.L.; LÓPEZ MORENO, J.I.; SANJUÁN, Y. (2014): «Holocene and "Little Ice Age" glacial activity in the Marboré Cirque, Monte Perdido Massif, Central Spanich Pyrenees». The Holocene, 24(11), 1439-1452.

GonZÁlez García, M.; SERRANO, E.; GonZÁlez TrueBA, J.J. (2012): «Distribución altitudinal de formas periglaciares en la Coma de la Paúl (Macizo de Posets, Pirineos)», en Avances de la Geomorfología en España 2010-2012, Actas de la XII Reunión Nacional de Geomorfología (Santander, 17-20 septiembre de 2012). Santander, 617-620.

GonZÁlez GARCÍA, M.; SERRANO, E.; GONZÁleZ TrUEBA, J.J. (2014): «Elaboración de un mapa térmico de suelos en la alta montaña de la Maladeta (Pirineo Central) ", en Avances, métodos y técnicas en el estudio del periglaciarismo (GóMEZ Ortiz, A., Salvador Franch, F., Oliva Franganillo, M. Y Salvà CAtArineu, M., Eds.). Barcelona, Publicacions i Edicions de la Universitat de Barcelona, 277- 285.

HAMILTON, L. (1988): «The development, age and present status of a rock glacier in the Posets Massif, Spanish Pyrenees». Pirineos, 131, 43-56.

Kellerer-PirKlbaUeR, A.; LiEB, G.K.; KleINFERChNer, H. (2012): «A new rock glacier inventory of the Eastern european Alps». Austrian Journal of Earth Sciences, 105 (2), 78-93.

KRAINER, K.; RIBIS, M. (2012): «A rock glacier inventory of the Tyrolean Alps (Austria)». Austrian Journal of Earth Sciences, 105 (2), 32-47. 
LAMPRE, F. (1994): «La línea de equilibrio glacial y los suelos helados en el Macizo de la Maladeta (Pirineo aragonés): Evolución desde la Pequeña Edad del Hielo y situación actual», en El glaciarismo surpirenaico: nuevas aportaciones (C. MARTÍ BONO Y J.M. GARCÍA RUíz, Eds.). Logroño, Geoforma Ediciones, 125-142.

LAMPRE, F. (1998): Estudio geomorfológico de Ballibierna (Macizo de la MaladetaPirineo Aragonés. Zaragoza, Publicaciones del Consejo de Protección de la Naturaleza de Aragón.

LILLEROREN, K.; ETZELMÜLlER, B. (2011): «A regional inventory of rock glaciers and ice-cored moraines in Norway». Geografiska Annaler, Serie A, Physical Geography, 93, 175-191.

LIU, J.; MiLlaR, C.I.; WeSTFALl, R.D.; ZEBKER, H.A. (2013): «Surface motion of active rock glaciers in the Sierra Nevada, California, USA: Inventory and a case study using InSAR». The Cryosphere, 7, 1109-1119.

Lugon, R.; Delaloyé, R.; Serrano, E.; Reynard, E.; Lambiel, C.; GonZÁlez TRUEBA, J.J. (2004): «Permafrost and Little Ice Age relationships, Posets massif, Central Pyrenees, Spain». Permafrost and Periglacial Processes, 15, 207-220.

MARTí, M.; SERRAT, D. (1990): «Los glaciares rocosos del Pirineo Catalán: Primeros resultados» en, Actas de la $1^{a}$ Reunión Nacional de Geomorfología (Teruel, 17-20 Septiembre 1990). Teruel, 191-201.

MARTÍ, M.; SERRAT, D (1995): «Les glaceres rocalloses pirinenques». Terra, Revista Catalana de Geografia, Cartografia i Ciències de la Terra, 25, 24-34.

MARTÍNEZ DE PiSÓN, E.; ARENILlAS PARRA, M. (1988): «Los glaciares actuales del Pirineo español», en La Nieve en el Pirineo Español. Madrid, MOPU, 29 -98.

MARTíNEZ DE PISÓN, E. (1989): «Morfología glaciar del Valle de Benasque (Pirineo Aragonés)». Eria, 18, 51-64.

MARTINI, M.A.; STRELIN, J.A.; Astini, R.A. (2013): «Inventario y caracterización morfoclimática de los glaciares de roca en la Cordillera Oriental argentina (entre $22^{\circ}$ y $\left.25^{\circ} \mathrm{S}\right) »$. Revista Mexicana de Ciencias Geológicas, 30 (3), 569-581.

MONNIER, S. (2006): Les glaciers-rocheux, objets géographiques. Analyse spatiale multiescalaire et investigations environnementales. Application aux Alpes de Vanoise. Thèse de Doctorat. Université Paris XII - Val de Marne-École Doctorale SIMME.

PÉRez SÁnchez, J.; SAlvador Franch, F.; SAlva CATARIneu, M.; Gómez OrTiz, A. (2014): «Catalogación de los glaciares rocosos del macizo del Puigmal (Pirineo Oriental). Primeros resultados», en Avances, métodos y técnicas en el estudio del periglaciarismo (GÓMEZ ORTIZ, A., SALVAdOR FrANCH, F., Oliva Franganillo, M. y Salvà Catarineu, M., Eds.). Barcelona, Publicacions i Edicions de la Universitat de Barcelona, 175-187.

Rangecroft, S.; Harrison, S.; Anderson, K.; Magrath, J.; Castel, A.P.; PACHECO, P. (2014): «A first Rock Glacier Inventory for the Bolivian Andes». Permafrost and Periglacial Processes, 25, 333-343.

SAnJose, J.J. ; Agudo, C. ; SERRANO, E. ; SILIO, F. (1992): «Auscultación topográfica y estudio fotogramétrico del glaciar rocoso de las Argualas (Pirineo aragonés): Datos Preliminares», en Estudios de geomorfología en España. II Reunión Nacional de Geomorfología, S.E.G. Murcia, 423-431. 
SCAPOZZA, C. (2008): Contribution à l'étude géomorphologique et géophysique des environnements périglaciaires des Alpes Tessinoises orientales. Master of Science in Geography. Faculté des géosciences et de l'environnement. UNIL-Université de Lausanne.

Schmid, M.O.; Baral, P.; Gruber, S.; Shahi, S.; Shrestha, T.; Stumm, D.; Wester, P. (2014): «Assessment of permafrost distribution maps in the Hindu Kush-Himalayan region using rock glaciers mapped in Google Earth». The Cryosphere Discuss., 8, 5293-5319.

Shrader, F. (1874): Carte du Mont-Perdu et de la Région Calcaire des Pyrénées. Expart des Mémoires de la Societé des Sciences Physiques et Naturelles de Bordeaus. Bordeaux. Imp. G. Chariol.

SERRANO, E.; RUBIO, V. (1989): «El glaciar rocoso activo de las Argualas (Pirineo Aragonés)». Eria, 19-20, 195-198.

Serrano, E.; Martínez de Pisón, E.; Martínez, R.; Cantarino, I.; NAVARro, J. (1991): «El glaciar noroccidental del Besiberri (Pirineo de Lérida)». Pirineos, 137, 95-109.

Serrano, E.; Agudo, C. (1998): «Los glaciares rocosos de los Pirineos. Implicaciones ambientales» en, Procesos biofísicos actuales en medios fríos. Estudios recientes (Gómez OrTíz, A., SAlvador Franch, F., Shulte, L., GARCÍA NAVARro, A., Eds.). Barcelona, Universitat de Barcelona, 133-154.

Serrano, E.; Agudo, C.; MARTíneZ DE PisÓN, E. (1999): «Rock glaciers in the Pyrenees». Permafrost and Periglacial Processes, 10, 101-106.

Serrano, E.; Agudo, C.; GonzÁlez TruebA, J.J. (2001): «El dominio del la alta montaña periglaciar en el macizo de Posets (Pirineo Aragonés)» en, Periglaciarismo en montaña y altas latitudes. IPA-España. Valladolid, Universidad de Valladolid, 163-184.

SERranO, E.; AGUdO, C. (2004): «Glaciares rocosos y deglaciación en la alta montaña de los Pirineos aragoneses (España)». Boletín de la Real Sociedad Española de Historia Natural, 99, 159-172.

Serrano, E.; Morales, C.; GonzÁlez Trueba, J.J.; Martín, R. (2009): «Cartografía del permafrost de montaña en los Pirineos españoles». Finisterra, XLIV, 87,45-54.

Serrano, E.; GonZÁlez TruebA, J.J.; SANJOSÉ, J.J. (2011): «Dinámica, evolución y estructura de los glaciares rocosos de los Pirineos». Cuadernos de Investigación Geográfica, 37, 145-170.

SERRANO, E. (2014): «Glaciares rocosos. Controversias y certidumbres», en Avances, métodos y técnicas en el estudio del periglaciarismo (GÓMEZ ORTIZ, A., Salvador Franch, F., Oliva Franganillo, M. Y Salvà Catarineu, M., Eds.). Barcelona, Publicacions i Edicions de la Universitat de Barcelona, 115-134. SOLÉ SABARÍs, L. (1951): Los Pirineos. El medio y el hombre. Barcelona, Ed. Martín. 
Figura 1. Glaciar rocoso de Contraix-Coll de Serradé (64) en el macizo de Punta Alta-Colomèrs: a) ortofoto infrarrojo color (superio izquierda); b) Detalle del frente (superior derecha); c) Vista general de contexto (inferior)
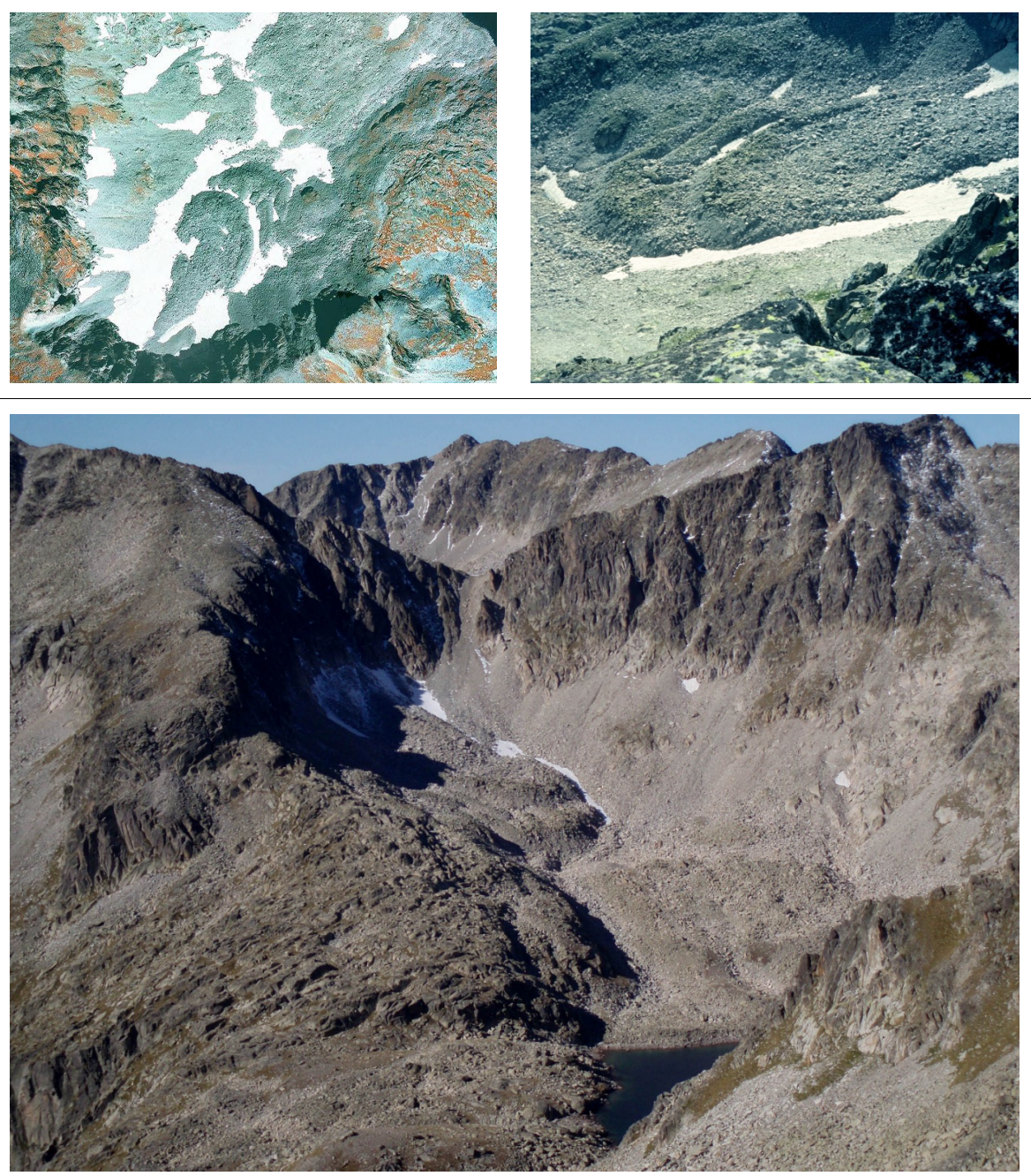

FUENTE: Imagen cenital de Vissir3-ICGC (superior izquierda) y fotografías del autor (Josep Ventura) 
Figura 2. a) Vista $3 D$ de la cabecera del Circo de Clarabide (Val Louron). De izquierda a derecha los glaciares rocosos de Pico de la Madera (34), Pic d'Aygues Tortes (33) y Pic Aygues Cluses (superior); b) Detalle del glaciar rocoso del Pic d'Aygues Cluses (inferior izquierda); c) Detalle del glaciar rocoso del Pico de la Madera (inferior derecha)
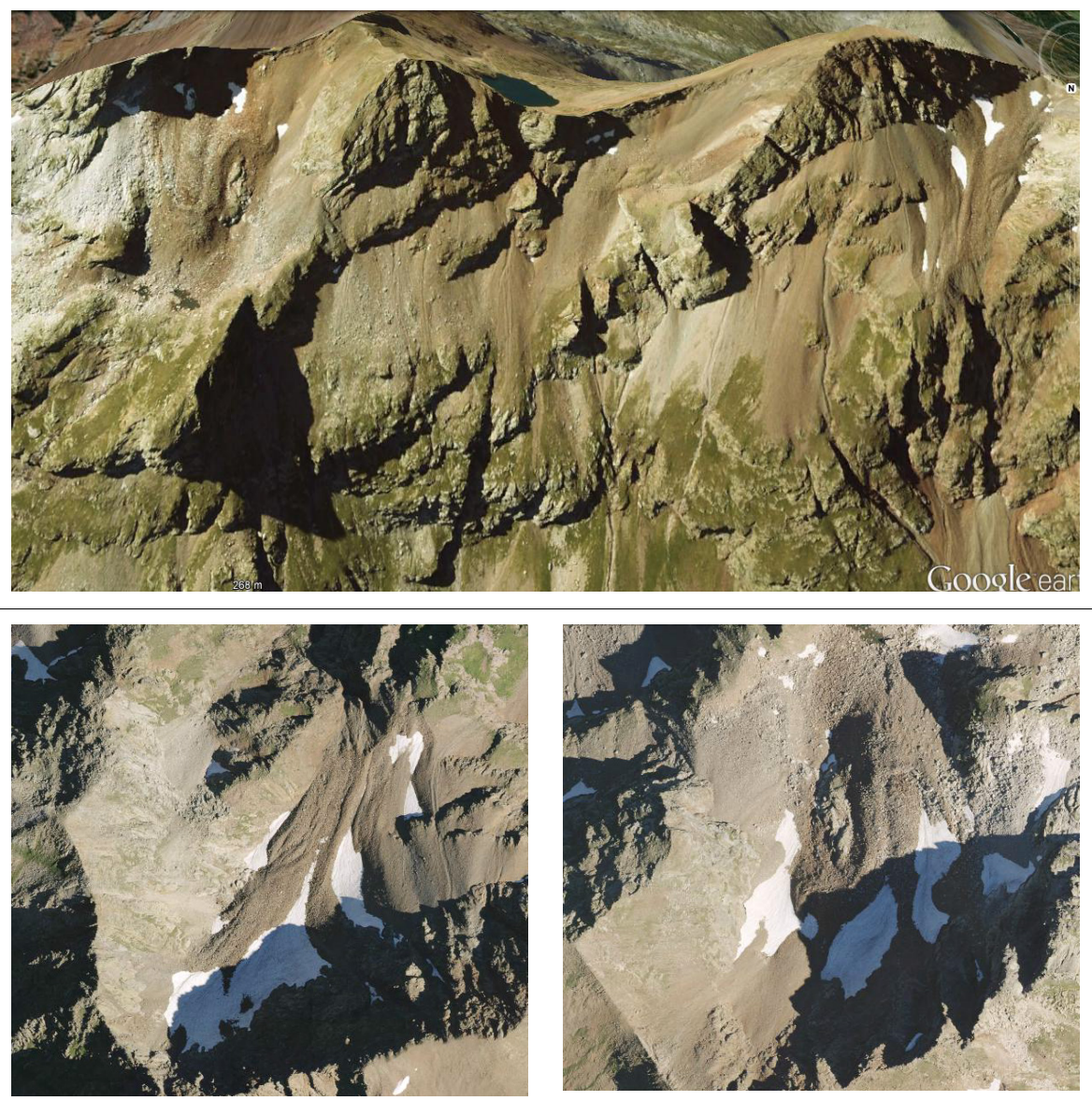

FUENTE: Imagen 3D de Google Earth (superior) y vistas cenitales de Géoportail (inferior) 
Figura 3. a) Vista 3D (arriba) del glaciar rocoso de Comalesbienes (61); b) Vista $3 D$ (abajo) del glaciar rocoso de Comalespales- Coll de Colieto (63). Ambos situados en el macizo de Punta Alta-Colomèrs
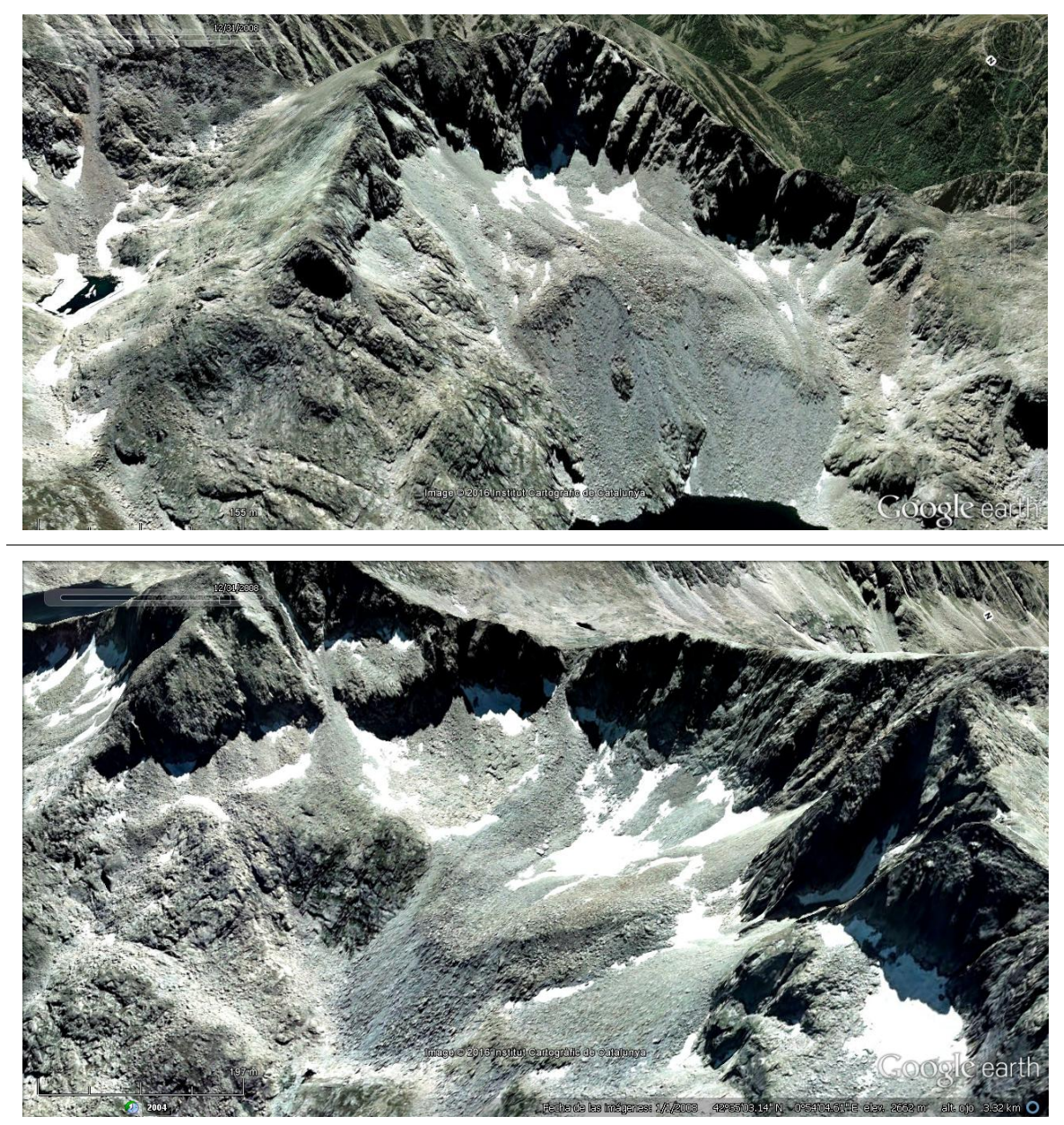

FUENTE: Imágenes 3D de Google Earth (superior e inferior) 
Figura 4. a) Detalle del Circo de Broate (macizo de la Pica d' Estats) donde se sitúan varios glaciares rocosos iniciales (70 y 71). El pequeño aparato situado en una posición central debido a sus reducidas dimensiones no se ha incluido en el nuevo inventario; b) Abajo a la izquierda, frente del glaciar rocoso de Broate $W$ (70); c) Abajo a la derecha, frente del glaciar rocoso del Pic de Gerri (74) en el macizo de Monteixo-Medacorba
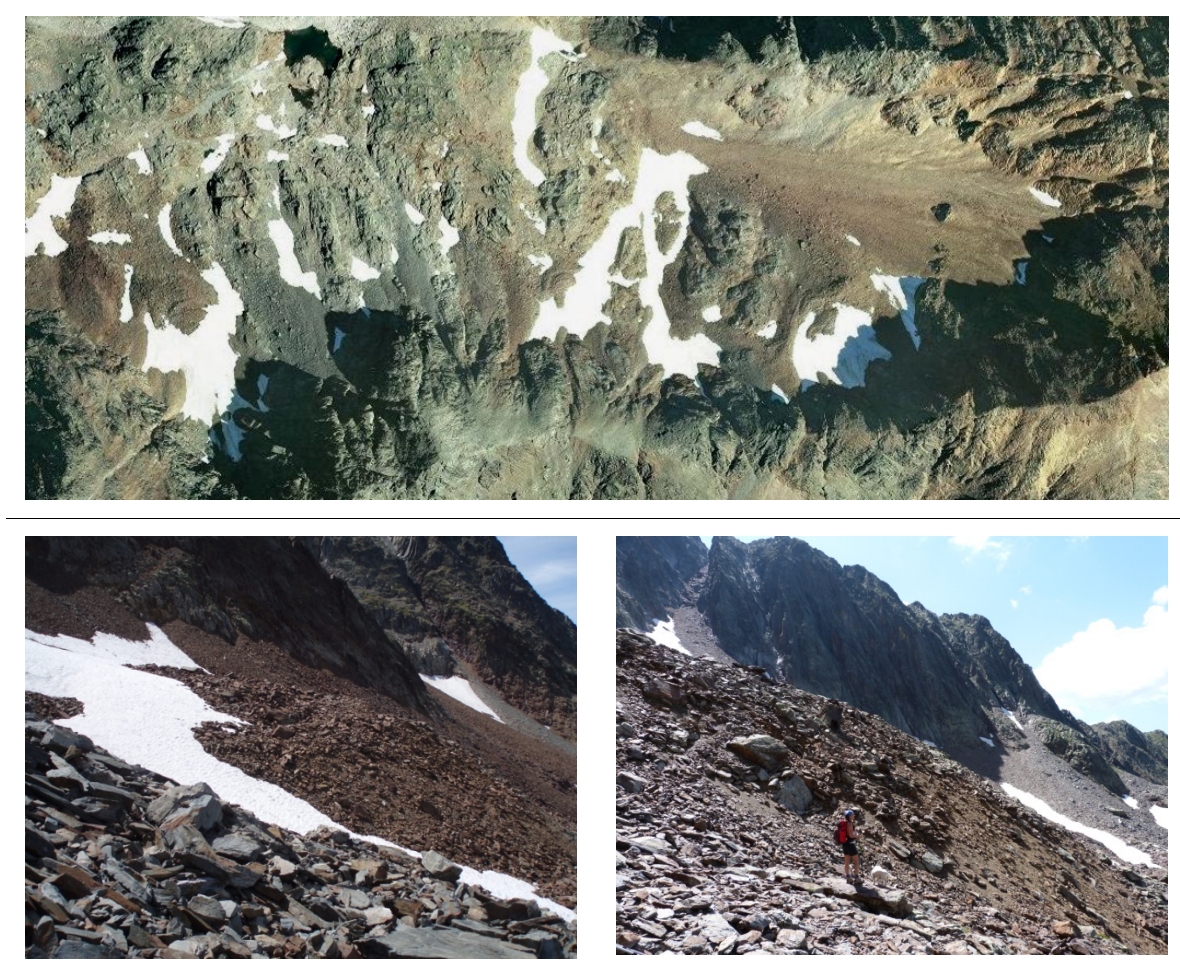

FUENTE: Imagen cenital de Vissir3-ICGC (superior) y fotografías del autor (Josep Ventura) 
Figura 5. a) Imagen superior, vista 3D del glaciar rocoso del Collado de AstazúMarboré (16) en el macizo de Monte Perdido; b) Imagen inferior, vista $3 D$ de los glaciares rocosos de Pico de Alba-2 (44) a la izquierda y de Pico de Alba-Cregüeña (46) a la derecha (macizo de la Maladeta).
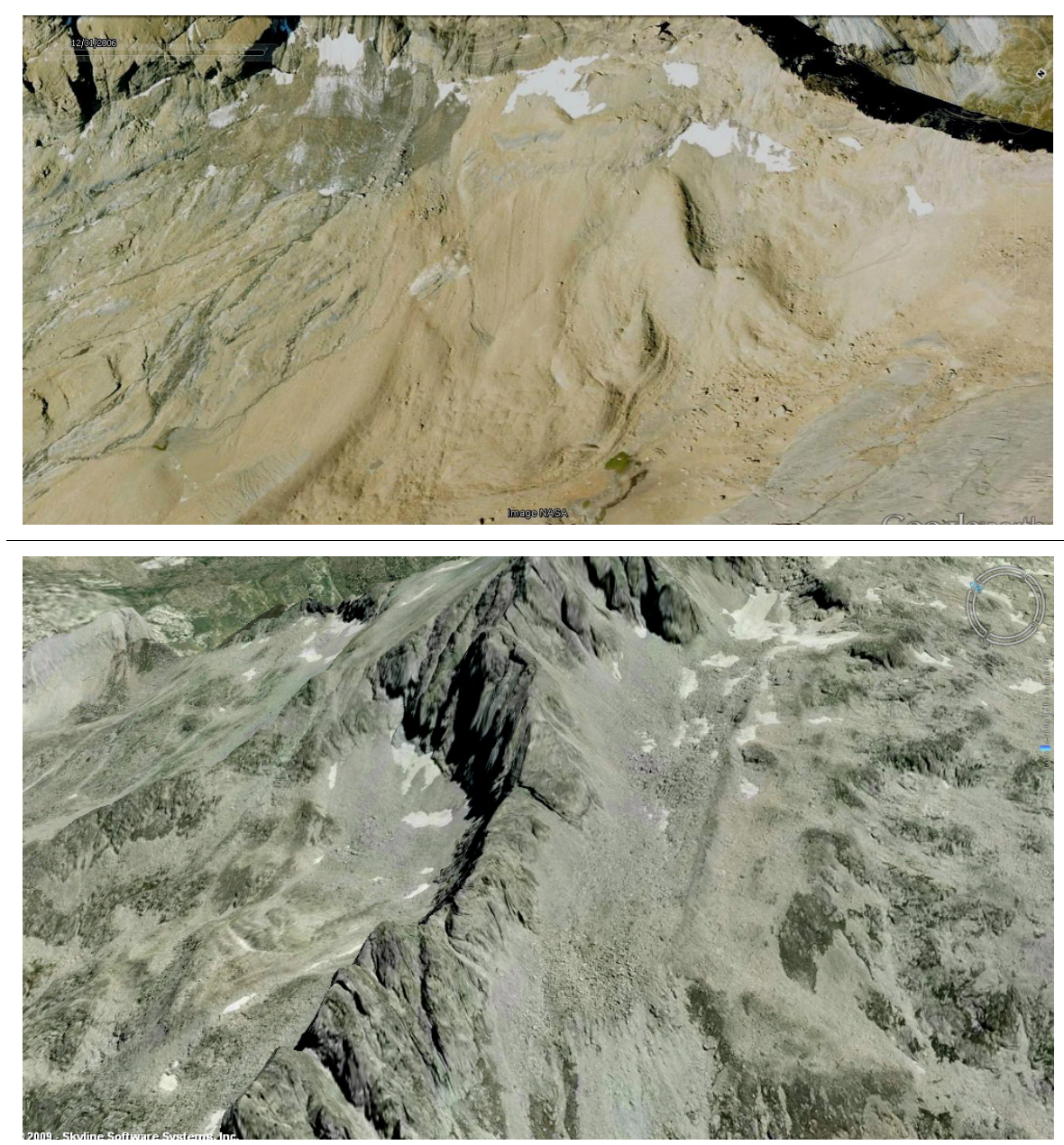

FUENTE: Imagen 3D de Google Earth (superior) e imagen 3D de Sitar Aragón3D (inferior) 
Figura 6. a) Superior izquierda, vista 3D del glaciar rocoso del Pic de la Fossa de Gegant (84) en el macizo de Puigmal-Carancà ; b) Superior derecha, ortofoto infrarrojo color del mismo glaciar rocoso (84); Imagen inferior, vista vertical del glaciar rocoso de la Pica del Canigó-Barbet (87)
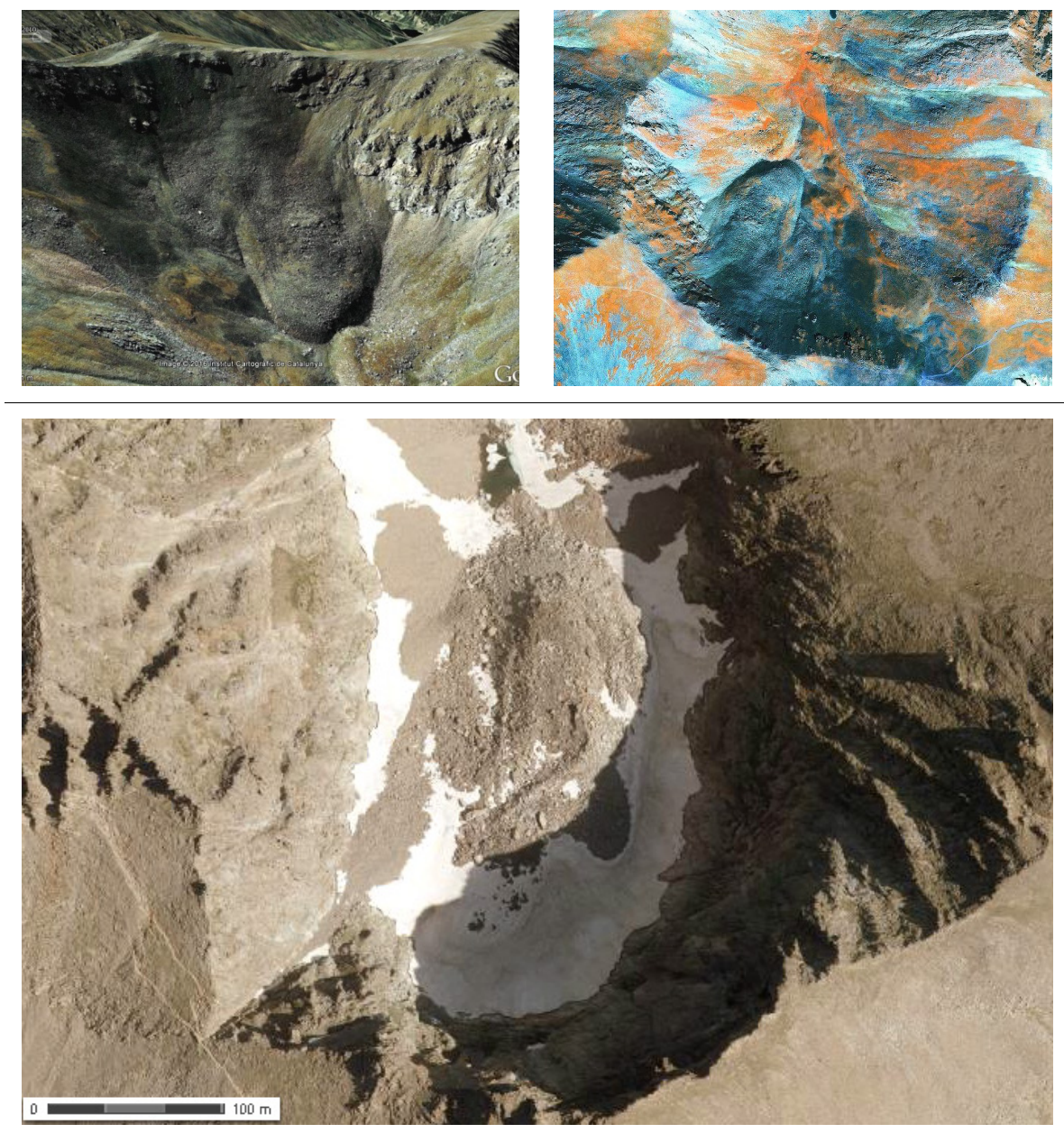

FUENTE: Imagen 3D de Google Earth (superior izquierda); vista cenital de Vissir3ICGC (superior derecha) y vista cenital de Géoportail (inferior) 
Tabla 5. Inventario de glaciares rocosos activos y potencialmente activos en los Pirineos (2016)

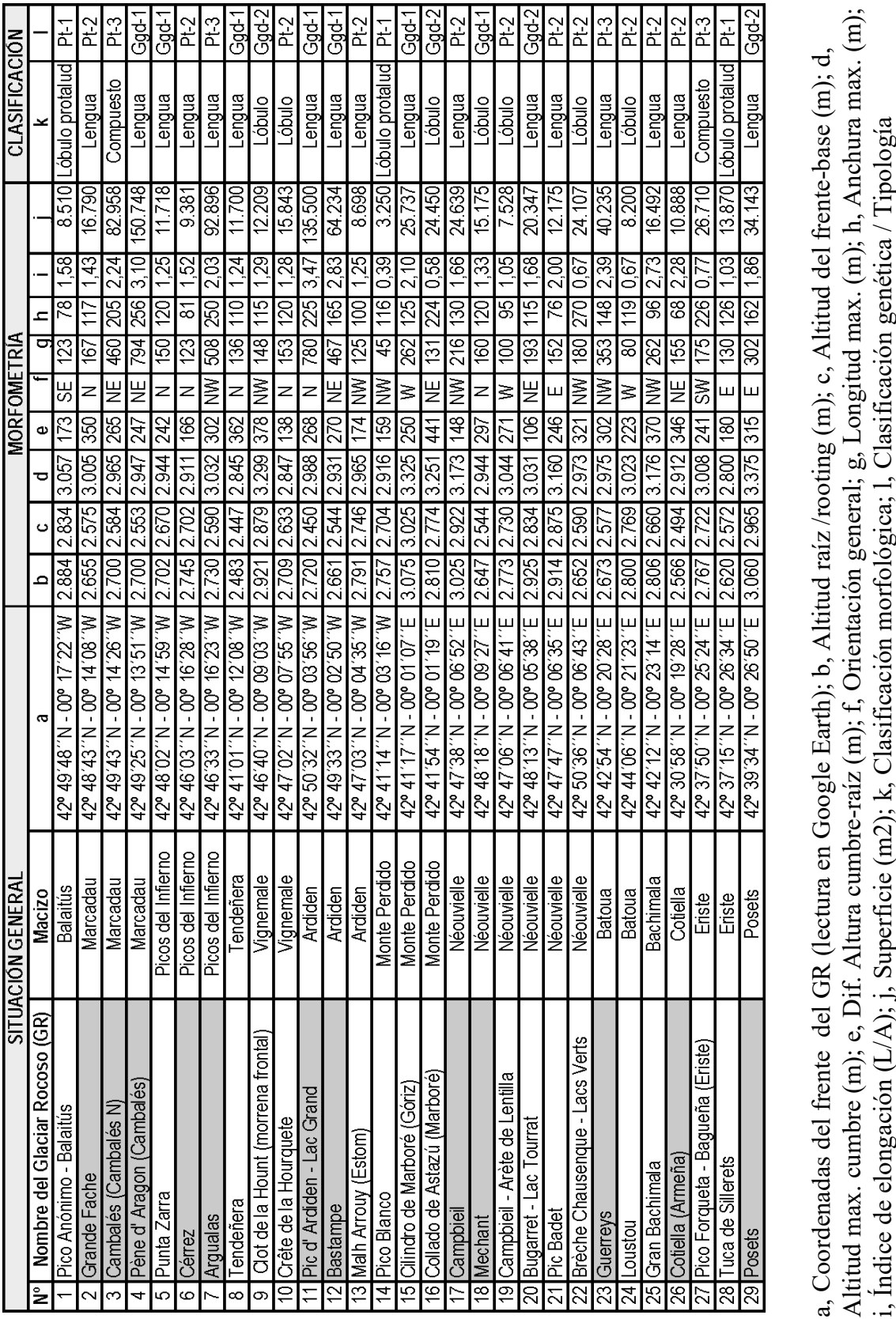


Identificación e inventario de potenciales glaciares rocosos activos en los Pirineos...

Tabla 5. (cont.)

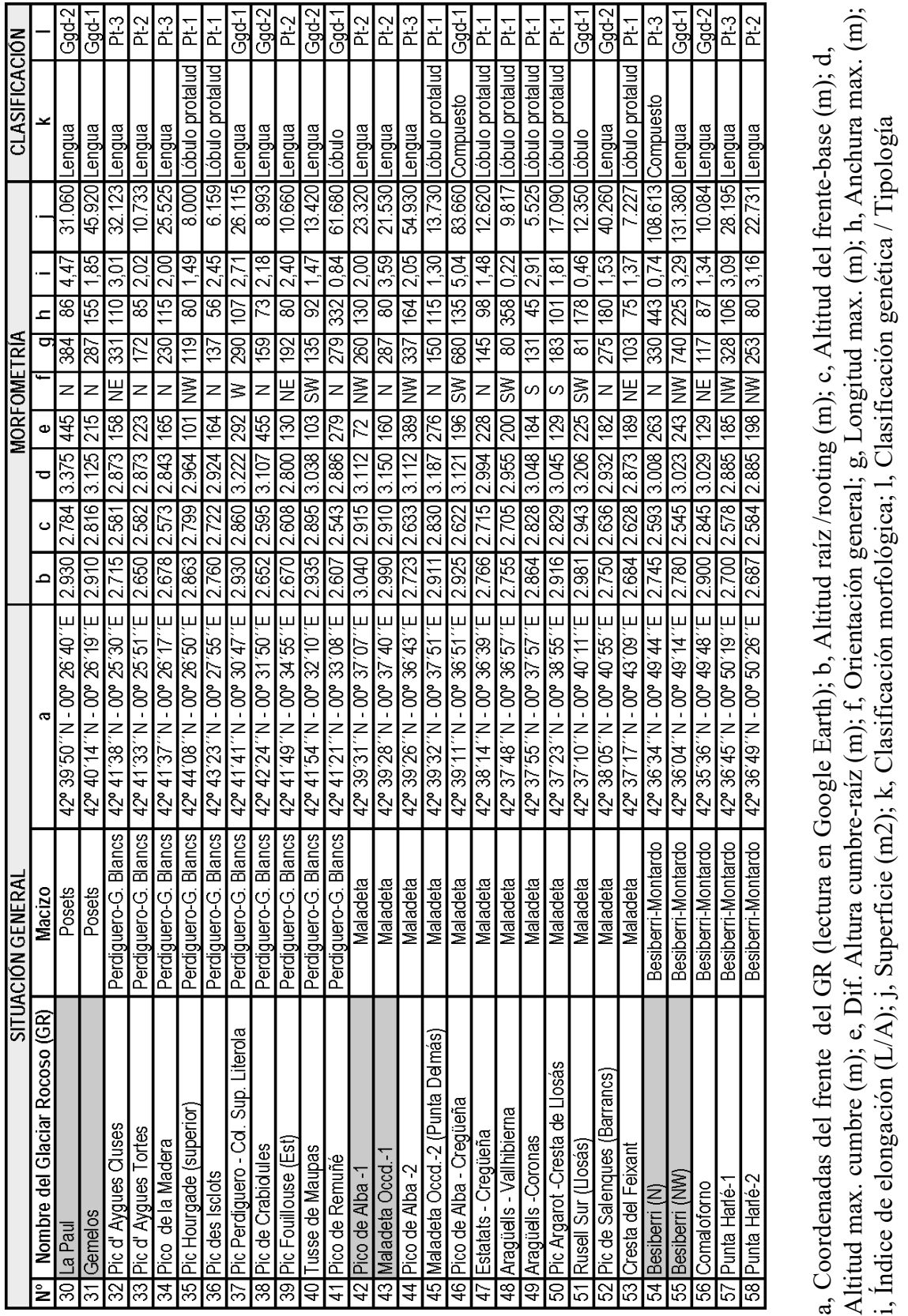


Tabla 5. (cont.)

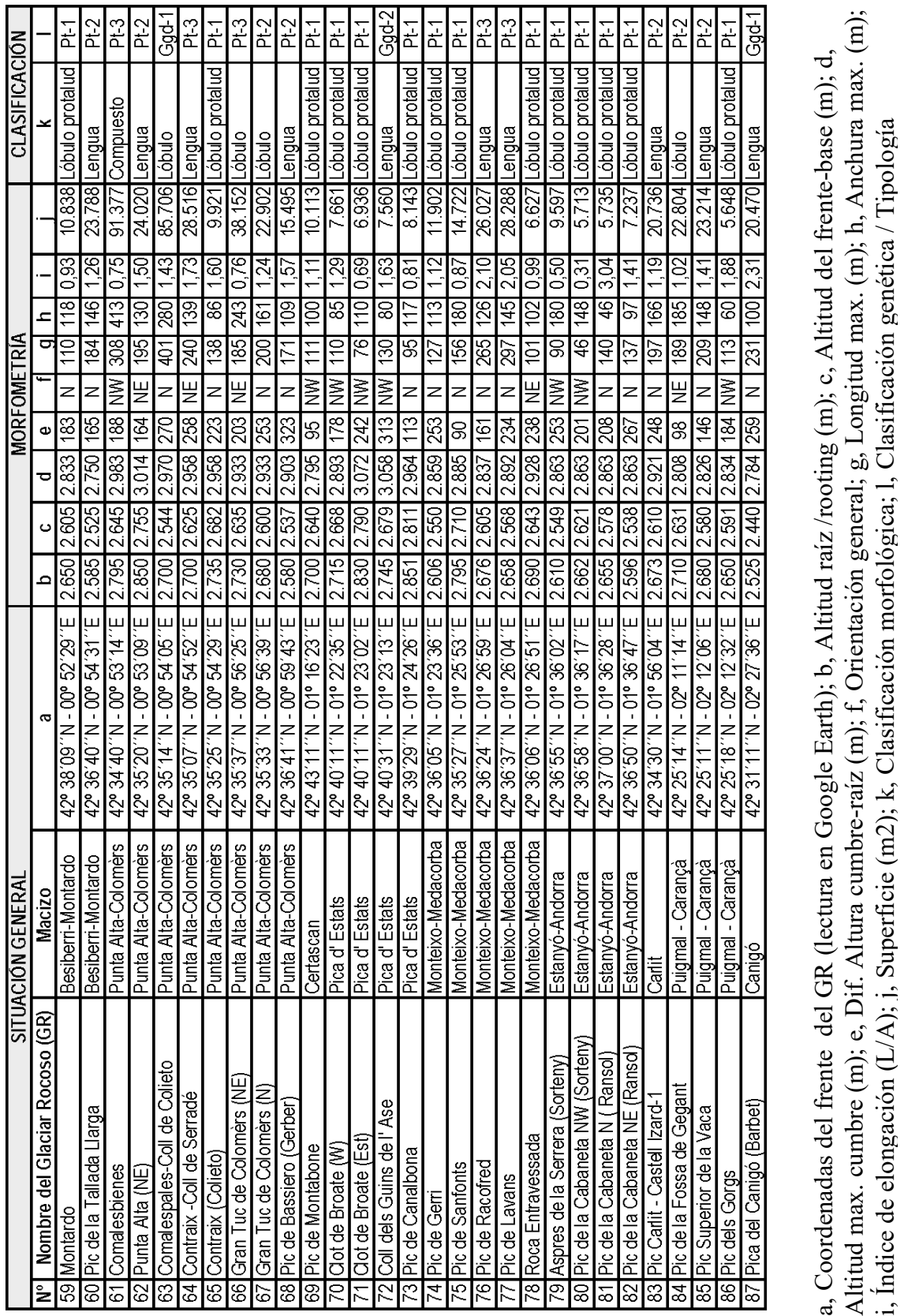

